\title{
Advantages of Electrochemical Polishing of Metals and Alloys in Ionic Liquids
}

\author{
Olga Lebedeva ${ }^{1} \mathbb{D}$, Dmitry Kultin ${ }^{1} \mathbb{D}$, Alexandre Zakharov ${ }^{2} \mathbb{D}$ and Leonid Kustov ${ }^{1,3,4, *}$ \\ 1 Department of Chemistry, Lomonosov Moscow State University, 119991 Moscow, Russia; \\ lebedeva@general.chem.msu.ru (O.L.); dkultin@general.chem.msu.ru (D.K.) \\ 2 Department of Fundamental Sciences, Moscow N.E. Bauman State Technical University, 2-ya Baumanskaya 5, \\ 105005 Moscow, Russia; zakhalex@bmstu.ru \\ 3 N.D. Zelinsky Institute of Organic Chemistry, Russian Academy of Sciences, Leninsky Prospect 47, \\ 119991 Moscow, Russia \\ 4 Institute of Ecology and Engineering, National Science and Technology University “MISiS", Leninsky \\ Prospect 4, 119049 Moscow, Russia \\ * Correspondence: 1mk@ioc.ac.ru; Tel.: +7-495-939-5261
}

Citation: Lebedeva, O.; Kultin, D.; Zakharov, A.; Kustov, L. Advantages of Electrochemical Polishing of Metals and Alloys in Ionic Liquids. Metals 2021, 11, 959. https:// doi.org/10.3390/met11060959

Academic Editor: Changdong Gu

Received: 8 May 2021

Accepted: 8 June 2021

Published: 14 June 2021

Publisher's Note: MDPI stays neutral with regard to jurisdictional claims in published maps and institutional affiliations.

Copyright: (c) 2021 by the authors. Licensee MDPI, Basel, Switzerland. This article is an open access article distributed under the terms and conditions of the Creative Commons Attribution (CC BY) license (https:// creativecommons.org/licenses/by/ $4.0 /)$.

\begin{abstract}
Electropolishing of metal surfaces is a benign alternative to mechanical treatment. Ionic liquids are considered as green electrolytes for the electropolishing of metals. They demonstrate a number of advantages in comparison with acid aqueous solutions and other methods of producing smooth or mirror-like surfaces that are required by diverse applications (medical instruments, special equipment, implants and prostheses, etc.). A wide window of electrochemical stability, recyclability, stability and tunability are just a few benefits provided by ionic liquids in the title application. An overview of the literature data on electropolishing of such metals as $\mathrm{Ti}, \mathrm{Ni}, \mathrm{Pt}, \mathrm{Cu}, \mathrm{Al}, \mathrm{U}, \mathrm{Sn}, \mathrm{Ag}, \mathrm{Nb}$, stainless steel and other alloys in ionic liquids is presented.
\end{abstract}

Keywords: polishing; electropolishing; ionic liquid; molten salt; metals and alloys; treatment of metal; anodization

\section{Introduction}

Anodic treatment is one of the most effective methods used in the finishing of metals and alloys to achieve a mirror-like state of the metal surface. The result of this process depends on a number of factors, including the properties and composition of metal and electrolyte, temperature, voltage, current density, time, and others [1-7].

There are various industrial applications requiring a particular quality of the metallic surface. Anodization results in different types of changes to the metal surface, such as etching, pitting, deflashing, passive film formation, nanostructure self-organization, deburring, trimming, smoothing and so on.

Anodization of metals and alloys has been studied in detail in aqueous solutions of various electrolytes [8]. However, water is electrochemically active at potentials of discharge of the majority of metals and can also take part in electrode reactions. On the other hand, ionic liquids [9] (IL) demonstrate larger electrochemical windows and are already used as electrolytes in medicine and industry [10].

Despite the essential advantages of ionic liquids and the growing number of their applications in electrochemical processes (e.g., for electrochemical polishing of metals and alloys), comprehensive review of the features, characteristics and chemical mechanisms of electropolishing in ionic liquids is lacking. This work is aimed the overview of recent investigations summarizing challenges and conditions of the employment of the ionic liquids based on organic cations in the electrochemical polishing of metals and alloys. 


\section{Electropolishing Mechanisms}

The light reflectance of the surface is known to be the immanent property of any metal. The majority of metals are strong reductive agents. Metals exposed to environmental molecular oxygen, water vapor, carbon dioxide, and so on form superficial oxides, hydroxides, nitrides, and salts, diminishing the reflectivity. The metal surface becomes dull due to the superficial films of these compounds. The tarnish of the metal surface is determined by both the properties and thickness of the superficial films. A film-free surface of the metal, for example, after mechanical treatment (abrasion), also reflects visible light well enough. The high reflectance of the mechanically polished metal surface is due to a great difference between the linear sizes of the superficial defects $(<1-10 \mathrm{~nm})$ and the wavelength of the visible light $(400-800 \mathrm{~nm})[11,12]$. When the wavelength of the visible light is near or greater than the sizes of asperities, the metal surface seems dull.

The metal surface dimness diminishing the reflectance in the optical region is essentially due to the light scattering on the film rather than on the defects of the metal surface. The surface light scattering is dependent on the ratio of the light wavelength and sizes of oxide film roughness.

Effective light scattering of oxidized surfaces is observed for many metals. Aluminum is a typical example proving this phenomenon. The aluminum oxide film is assumed to produce a dull finish on the metal surface, owing to its considerable thickness $(\sim 0.5-1 \mu \mathrm{m})[13,14]$. The light scattering on natural oxidized copper is also due to the oxide film, the thickness of which was calculated to be about $627 \mathrm{~nm}$ [15]. The oxide film thicknesses on chromium [16], nickel [17], and titanium [18,19] are considerably smaller (3-7 nm) than the wavelength of visible light. That is why metallic $\mathrm{Cr}, \mathrm{Ni}$, and Ti maintain the high brightness of their naturally oxidized surfaces.

Smoothing to obtain a mirror-like metal surface implies, first of all, a removal of metal oxide excess. Mechanical treatment of the oxidized metal surface (e.g., abrasion, buffing, burnishing, etc.) may be successfully used to give workpieces a high polish. On the other hand, chemical dissolution of the superficial compounds based on the reaction with acids does not always lead to a mirror-like metal surface, because of nonselective action of hydrogen ions. In most cases, acidic treatment results in etching or pitting of the metal surface [20].

A glossy metal surface can be formed by both anodic and cathodic polarizations of electrodes. A wide-spread cathodic reduction does not refer to the electropolishing processes. Usually, electrochemical polishing is considered as an anodic reaction. Electrochemical oxidation provides an alternative way to achieve the required result. An anodic polarization of a metal electrode to be focused on electropolishing imposes certain requirements for the chemical nature of the electrolyte, which must be, first of all, stable enough at the potentials applied. Aqueous solutions of strong electrolytes hardly fulfill these requirements. The use of aqueous solutions is evidently restricted in the fabrication of mirror-like surfaces of metals or alloys on account of the competitive side-reaction of water oxidation to molecular oxygen (Equation (1)) [3].

$$
2 \mathrm{H}_{2} \mathrm{O}-4 \mathrm{e}^{-} \rightarrow \mathrm{O}_{2}+4 \mathrm{H}^{+}
$$

Although water is a less active reducing agent compared with base metals, the probability of Equation (1) in aqueous solutions is high enough. Electrochemical oxygen evolution favors the appearance of secondary metal oxide films. Only a minority of metals can be polished to a bright surface by anodization in aqueous solutions of acids. These metals should be inert to acids and should be covered with thin passive oxide films (stainless steel, nickel, copper, platinum, etc.). The result of electropolishing for the majority of the industrially important metals in acid solutions is etching or pitting. Electropolishing being targeted at the fabrication of a mirror-like metal surface implies a dissolution of oxide films as the main reason for diffuse light scattering. 
Electrochemical oxidation of water evidently occurs on the metal surface due to the diffusion of water molecules within the pores of the oxide layer. $\mathrm{H}^{+}$ions, being electrochemically formed, move in a reverse direction towards the cathode and may react with metal oxide according to Equation (2). The migration rate of the hydrogen ions to the cathode and the thickness of the oxide film determines the probability of the occurrence of the heterogeneous chemical Equation (2) providing the dissolution of the oxide film.

$$
\mathrm{M}_{x} \mathrm{O}_{y}+2 y \mathrm{H}^{+}=x \mathrm{M}^{+(2 y / x)}+y \mathrm{H}_{2} \mathrm{O}
$$

The probability of Equation (2) clearly decreases with the increase in the $\mathrm{H}^{+}$migration rate to the cathode. The $\mathrm{H}^{+}$migration rate depends on the viscosity of the electrolyte; the porosity, thickness, and chemical properties of the oxide film; as well as temperature, current density, voltage, and other factors [1-3]. If the electropolishing occurs in acidic solutions, Equation (2) becomes the main process [1,3-5].

In recent years, ionic liquids [10,21-23] tend to be actively used as electrolytes for a lot of electrochemical processes. Ionic liquids are of growing interest due to their outstanding advantages against aqueous solutions. Electrochemical potentials of discharge of the ionic liquid ions are significantly shifted to larger values (electrochemical window) that exclude all side reactions with the solvent participation.

Among a set of industrial processes, electropolishing of metals and alloys is known to be particularly sensitive to the chemical nature of the electrolyte. There are diverse areas that require mirror-like metal surfaces (e.g., microelectronics [24], construction of space technics and aerospace frames [25], medical instruments [26,27], biocompatible alloys [28-33], and others). Electropolishing of metals and alloys is similar in its function to dissolution during the passage of current to provide the removal of the surface roughness and to achieve a smooth surface.

The upper layers of the surface of base metals and alloys are known to consist of natural oxide films of different compositions covering crystalline metal defects. The metal surface smoothing to obtain a brilliant reflectance is a sequence of complex processes, including not only the removal of metal oxides, but also the controlled elimination of defects of the surface. It is evident that electrochemical removal of oxide films and metal roughness represents different consecutive processes taking place at the interface of the electrode.

Electropolishing efficiency is dependent on the chemical properties of the films, which are known to be individual for each metal or alloy. In general, the mechanism of metal surface electropolishing implies discrepant rates of the removal of covering films and proper metal atoms from different sites of the surface. The oxide films are often removed owing to Equation (2), both in aqueous and non-aqueous solutions. In the latter case, hydrogen ions appear after anodic oxidation of residual water. After oxide film removal, the smoothing of the surface occurs with a higher current density on the edges of the crystal structure.

A chemical dissolution of the superficial oxides according to Equation (2) is not the sole process of oxide film removal. In the absence or lack of hydrogen ions (e.g., in ionic liquids), the electrochemical dissolution of oxides becomes more probable and may undergo one/two-electron processes (Equations (3) and (4)) [15].

$$
\begin{aligned}
& \mathrm{M}_{2} \mathrm{O}-1 \mathrm{e}^{-} \rightarrow \mathrm{MO}+\mathrm{M}^{+} \\
& \mathrm{MO}-2 \mathrm{e}^{-} \rightarrow \mathrm{M}^{2+}+\mathrm{O}_{\text {ads }}
\end{aligned}
$$

Equations (3) and (4) are competing with Equation (2) in IL, particularly for the low-valence metals (copper, tin, lead, etc.). 


\section{Electropolishing of Metals and Alloys}

\subsection{Stainless Steel}

Stainless steels are the most widespread construction materials used in various branches of industry and medicine [34-36]. The high surface quality is required for the fabrication of mirrors and instruments (e.g., in medicine) to exclude undesirable corrosion processes. The surface homogeneity may be effectively achieved by electrochemical polishing.

A substantial progress in electrochemical polishing of stainless steels was attained via using ionic liquids [2,34-36]. Ionic liquids based on choline chloride (2-hydroxyethyltrimethyl ammonium chloride) were used for the first time to smooth the surface of metals and alloys [1-3]. Choline chloride, being a crystalline substance under room temperature, is mixed with ethylene glycol to get a viscous conducting liquid. The mixture of choline chloride with ethylene glycol in a 1:2 molar ratio (ethaline) exhibited high efficiency in metal finishing [2,3].

The metal dissolution mechanism in ethaline was shown to be different from that in aqueous acid solutions. The result of stainless steel electropolishing in ethaline is strongly dependent on the current density. The electropolishing was found to occur isotropically at a higher current density $\left(>50 \mathrm{~mA} \mathrm{~cm}^{-2}\right)$ to yield a mirror-like sample. Otherwise, providing that the current density was lower $\left(<50 \mathrm{~mA} \mathrm{~cm}^{-2}\right)$, the oxide film was removed non-uniformly and no polishing was observed. The sample finish, in this case, was dull rather than mirror-like. The difference in the surface state of two regions of stainless steel polished with higher (right) and lower (left) current densities is shown in Figure 1 [35]. The dissolution of the oxide film of stainless steel in IL brings about pitting rather than the polishing observed at a higher current density.

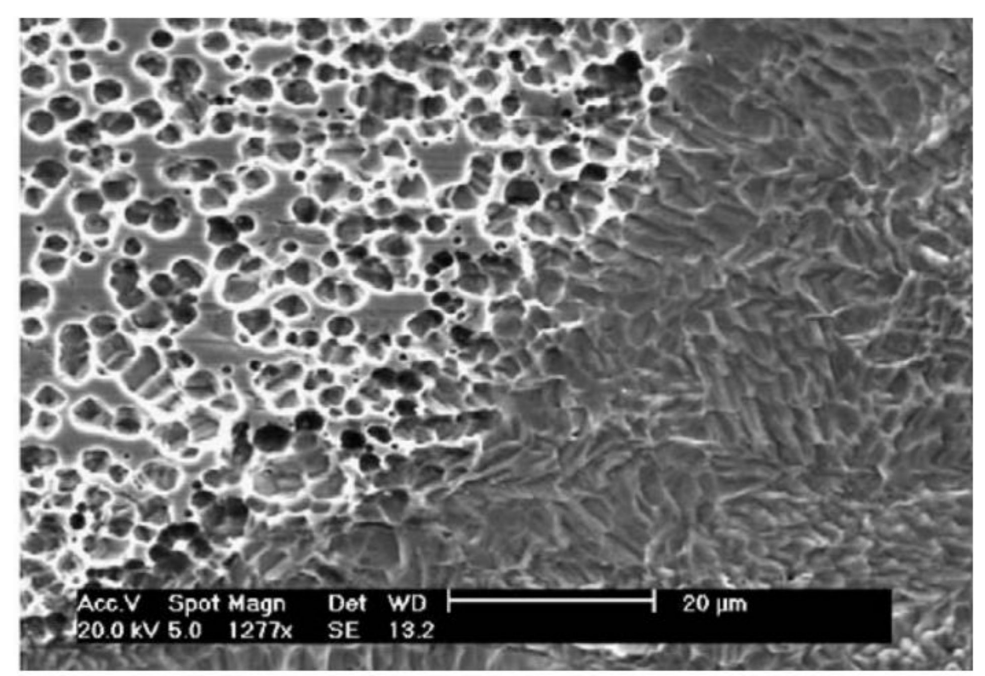

Figure 1. SEM images of stainless steel 316 etched in a mixture of choline chloride-ethylene glycol (1:2) for $10 \mathrm{~min}$ at $45^{\circ} \mathrm{C}$ at $7.0 \mathrm{~V}\left(\mathrm{I}_{3}{ }^{-} / \mathrm{I}^{-}\right)$(reprinted with permission from ref. [35]; Copyright 2005 Elsevier).

The electrochemical behavior of 316 stainless steel in ethaline showed that the quality of polishing was determined not only by the current density. The authors noted that traces of water resulted in widening of the current density window over which a mirror-like surface could be detected [35]. However, pitting of the surface of the stainless steel is only observed when the water content in IL exceeds $10 \%$.

The effect of water was explained by decreasing electrolyte viscosity and increasing electric conductivity. The authors do not rule out that the increase in the water concentration leads to secondary film formation of the insoluble metal salt. The rate-determining step of 316 stainless steel polishing was supposed to depend on the $\mathrm{Cl}^{-}$migration rate to the electrode.

The behavior of various samples of the mechanically abraded stainless steels $(410,302$, 304,316 , and 347) as disc working electrodes was studied under anodization in ethaline [36]. It was established that no changes in the surface composition of the samples were observed 
after the electrochemical polishing, and no dealloying of the steels was detected. The SEM image of the sample of stainless steel 304 (Figure 2) showed that a grain boundary pattern typical for the stainless steel samples disappeared in the untreated region after anodization. It was shown also that breakdown of the oxide film was the rate-limiting factor in electropolishing. The desired optically bright finishing of the samples was achieved by electropolishing of the above stainless steels, which seemed to depend on the performance of the oxide film removal, and was observed only for stainless steel 410 .
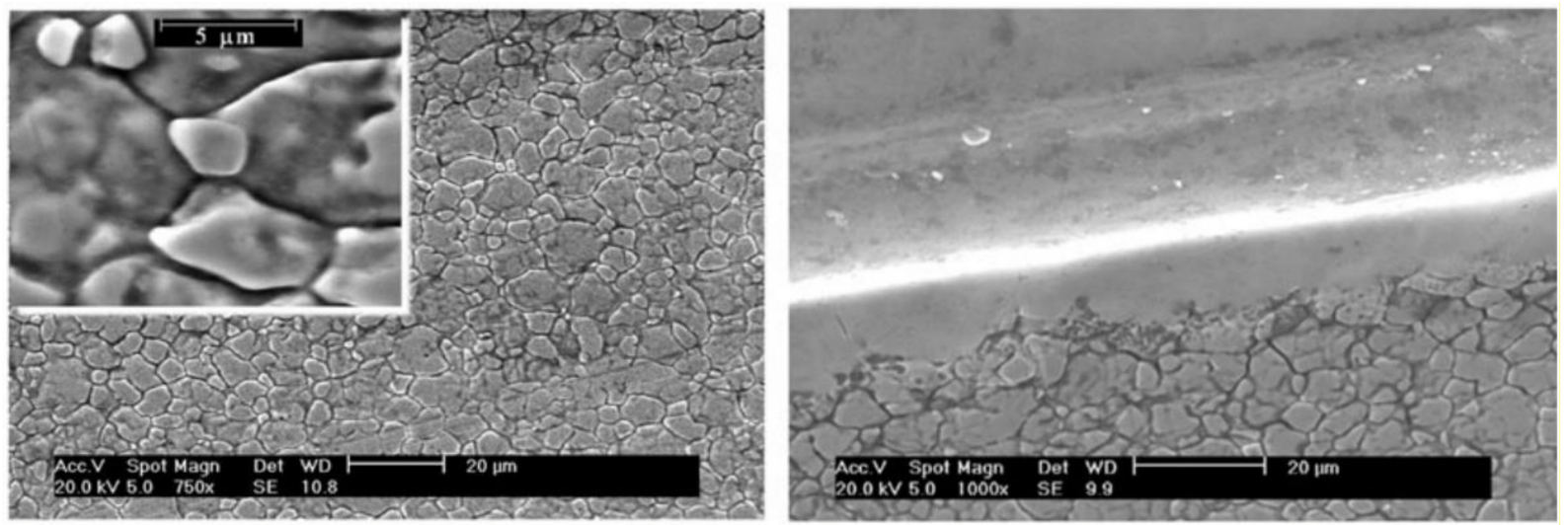

Figure 2. SEM image of the unpolished stainless steel 304 region (left) and SEM image of stainless steel 304 (right), showing transition between polished (top) and unpolished (bottom) regions of the sample after electrochemical polishing in a choline chloride-ethylene glycol mixture (reprinted with permission from ref. [36]; Copyright 2006 The Owner Societies).

The above-mentioned choline chloride-ethylene glycol mixture was also used for electrochemical study of alloys based on $\mathrm{Ni}, \mathrm{Ti}, \mathrm{Co}$, and $\mathrm{Cr}$, as well as 316L stainless steel [2,34-37]. Surface properties of these materials are of particular importance for medicine and biology. The alloys are widely used for prosthetic artificial limb replacements and for fabricating endovascular stents for coronary arteries [36].

The authors of [37] claimed that electropolishing of the $\mathrm{Ni}-\mathrm{Ti}$ (Nitinol) and $\mathrm{Co}-\mathrm{Cr}$ alloys and 316L stainless steel in ethaline at $70^{\circ} \mathrm{C}$ achieved shiny surfaces of the samples, with high optical reflectivity. The authors noted that all the samples of the shape memory alloys demonstrated surfaces with smoother appearance and feel.

According to EDX data, electropolishing of the above alloys in ethaline results in no selective surface leaching of any element of the alloys and allows the surface properties (hardness, toughness, biocompatibility) to be kept constant, which is of high importance for materials in medicine [37].

Ionic liquids based on organic cations such as imidazolium, pyridinium, and so on (Figure 3) also exhibit high efficiency in electrochemical polishing of some metals and alloys $[15,38,39]$. Counterions are usually presented by inorganic anions such as $\mathrm{BF}_{4}{ }^{-}$, $\mathrm{PF}_{6}{ }^{-}, \mathrm{N}\left(\mathrm{SO}_{2} \mathrm{CF}_{3}\right)_{2}{ }^{-}, \mathrm{Cl}^{-}$, and so on $[20,22]$.
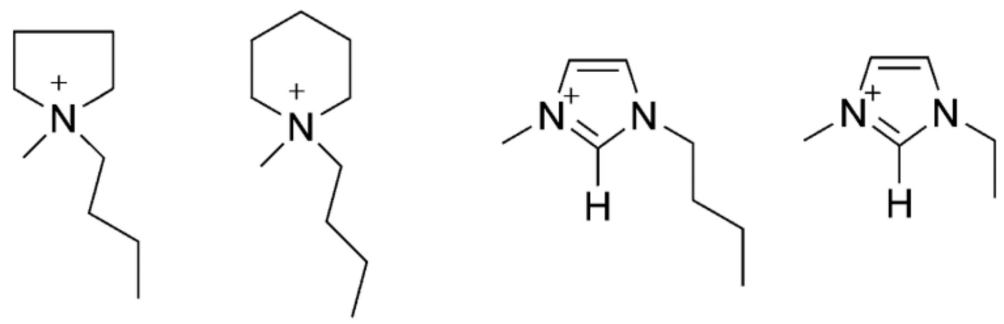

Figure 3. Structures of some cations of ionic liquids. 


\subsection{Titanium and Alloys}

A great number of publications have been dedicated to electrochemical finishing of titanium and its alloys [38-44]. These materials attract attention as objects for electropolishing to obtain the high-quality surface required for medicine and related areas. Polished titanium and its alloys exhibit extremely high resistance against electrochemical corrosion, which is of particular importance for the chemical industry and biomedical engineering of biocompatible materials [41,42]. These materials are needed for the formation of fibrous soft tissue capsules or for prostheses [41,42]. The chemical inertness of titanium and its alloys is known to be due to a thin passive oxide surface film, which is stable against chemical treatment and anodization.

Electropolishing of metallic Ti was studied in ethaline [42]. The authors found that anodization of Ti in ethaline resulted in smooth metallic surfaces with about $5 \mathrm{~nm}$ roughness. The mirror-like finishing of the Ti electrode was achieved at a constant voltage of $6 \mathrm{~V}$ for $30 \mathrm{~min}$ at $20^{\circ} \mathrm{C}$ under potentiostatic conditions. The authors noted that no gas evolution was observed under the above conditions.

The mechanism of the Ti electropolishing in ethaline was also considered [42]. It was proposed that $\mathrm{Ti}$ was dissolved primarily from the salient sites to form a $\mathrm{TiCl}_{4}$ film at the interfacial regions. The surface morphology of Ti was studied by SEM and AFM techniques (Figure 4). AFM measurements showed that electropolishing of a Ti sheet resulted in isotropic etching across the whole sample and effective mirror-like reflectivity.

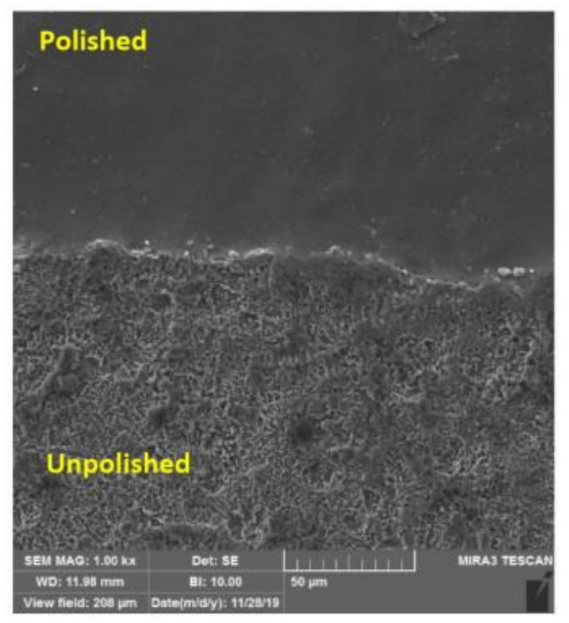

a
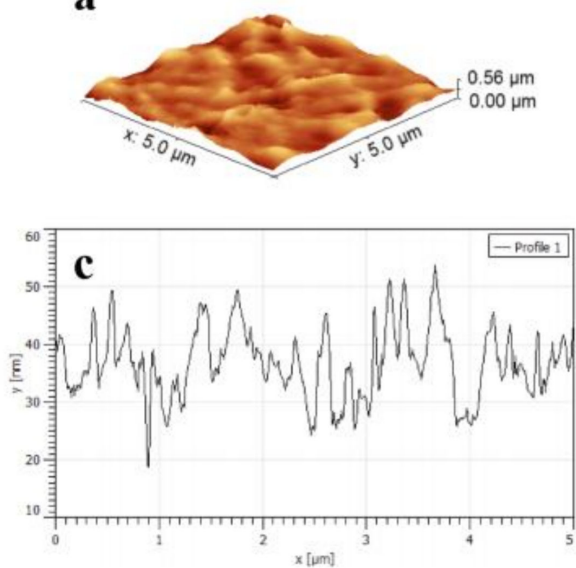
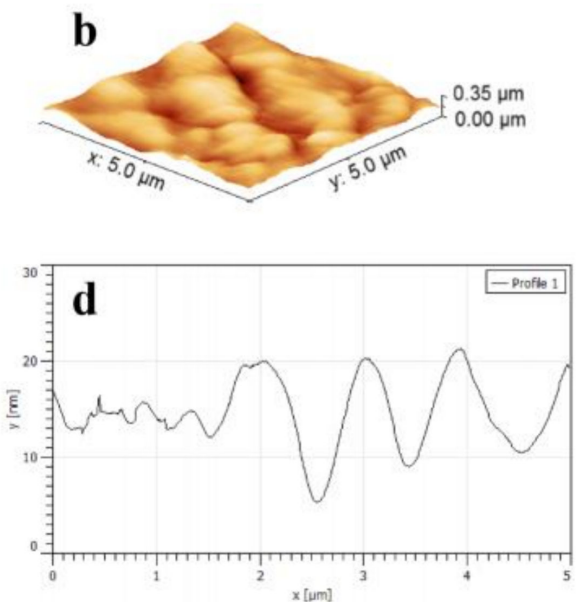

Figure 4. SEM (left) and AFM (right) images of Ti samples before electropolishing (a,c) and after electropolishing (b,d) (reprinted with permission from ref. [42]; Copyright 2020 by the author(s), published by the Electrochemical Society of Japan).

An average surface roughness of $5.7 \mathrm{~nm}$ was achieved after electropolishing at 6-10 V for $30 \mathrm{~min}$ (the initial sample had a roughness of $118.8 \mathrm{~nm}$ ) [42].

The mixtures of choline chloride $(\mathrm{ChCl})$ with ethanol $(1: 4$ molar ratio) and choline chloride with methanol-butanol (1:6:2 molar ratio) also were successively used for electrochemical polishing of Ti under potentiostatic conditions ( 2 and $1.2 \mathrm{~V}$, respectively) [43]. The state of the metallic titanium surface before and after electropolishing in choline chloride mixtures with alcohols is illustrated in Figure 5.

According to the SEM and AFM data, nanoscale polishing of pure titanium was achieved for $40 \mathrm{~min}$, the initial roughness of the sample $(120.5 \mathrm{~nm})$ being reduced to 0.10 and $0.66 \mathrm{~nm}$ in choline chloride-ethanol and choline chloride-methanol-butanol mixtures, respectively [43]. No anodic gas evolution occurred when butanol was added to IL.

The authors of [43] supposed that the low onset voltage in choline chloride mixtures with alcohols compared with ethylene glycol can be explained by the low viscosity of the electrolyte solution. The importance of the electrolyte viscosity in electropolishing was proved also for $\mathrm{Ag}, \mathrm{Au}, \mathrm{Co}, \mathrm{Cu}, \mathrm{Fe}, \mathrm{Ni}, \mathrm{Pb}, \mathrm{Sn}$, and $\mathrm{Zn}$ [2] in ethaline and 1-butyl-3methylimidazolium chloride ( 16 and $142 \mathrm{cP}$ at $70{ }^{\circ} \mathrm{C}$, respectively). The current density 
was found to increase with the rise in temperature, owing to the reduced viscosity of the electrolyte and the change in solubility of the oxide/salt film formed. The passive film formation was observed for the metals with a low dissolution potential ( $\mathrm{Pb}, \mathrm{Sn}, \mathrm{Zn})$. The electrochemical behavior of the majority of metals was similar in both electrolytes due to the formation of chloride complexes, which can block the surface of the electrode.

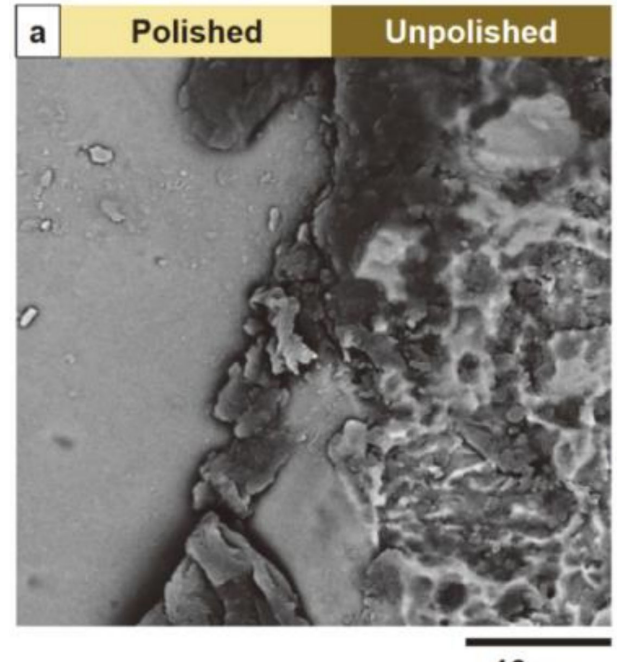

$10 \mu \mathrm{m}$

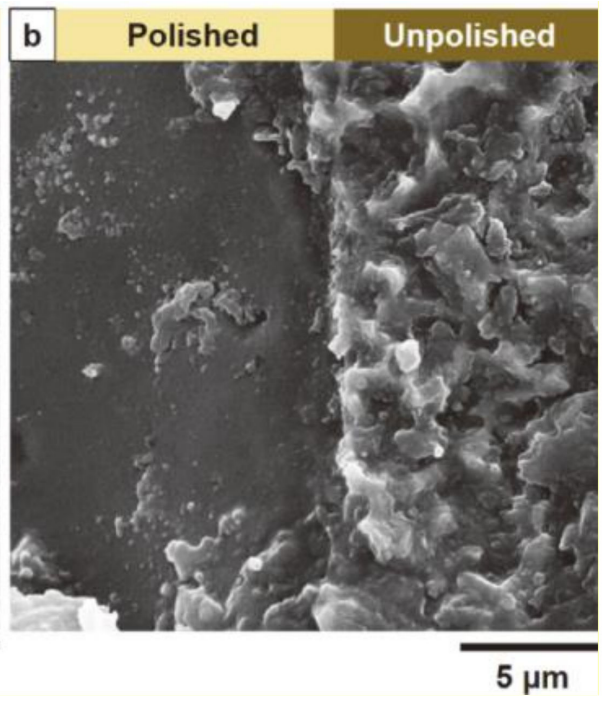

Figure 5. SEM images of the pure metallic Ti sample in (a) ChCl-MeOH- $n$-BuOH (1.2 V) and (b) $\mathrm{ChCl}-\mathrm{EtOH}(2 \mathrm{~V}) ; 2{ }^{\circ} \mathrm{C}, 40 \mathrm{~min}$ (reprinted with permission from ref. [43]; Copyright 2019 The Electrochemical Society of Japan).

Electrochemical behavior of $\mathrm{Ti}$ was studied in trimethyl- $n$-hexyl ammonium bis (trifluoromethyl)sulfonyl imide IL [40], (TMHA) $\mathrm{NTf}_{2}$, by means of cyclic voltammetry at $50{ }^{\circ} \mathrm{C}$. The electropolishing effect of $\mathrm{Ti}$ in (TMHA) $\mathrm{NTf}_{2}$ to form shiny silver titanium was observed only after preliminary mechanical treatment of Ti.

The authors studied in detail (using cyclic voltammetry, XRF analysis) the mechanism of anodic dissolution of titanium in (TMHA) $\mathrm{NTf}_{2}$ and concluded that the titanium anodic oxidation under experimental conditions occurred with the formation of $\mathrm{Ti}^{2+}$ or $\mathrm{Ti}^{3+}$ ions. The formation of a surface oxide film according to Equation (5) was supposed to hinder the anodic dissolution of the metal [40].

$$
\mathrm{Ti}+x \mathrm{H}_{2} \mathrm{O} \rightarrow \mathrm{TiO}_{x}+2 x \mathrm{H}^{+}+2 x \mathrm{e}^{-}(x \text { unknown })
$$

The electropolishing of titanium was also investigated in ionic liquids based on the 1buthyl-1-methylimidazolium (Bmim) cation and different anions $\left(\mathrm{NTf}_{2}{ }^{-}, \mathrm{BF}_{4}{ }^{-}, \mathrm{PF}_{6}{ }^{-}\right.$, and $\mathrm{Cl}^{-}$) [38]. It was found that the cation nature of IL did not affect the result of anodization in $\mathrm{BmimNTf}_{2}, \mathrm{BmimBF}_{4}$, and $\mathrm{BmimPF}_{6}$. The effective electropolishing of titanium was observed for $\mathrm{BmimNTf}_{2}, \mathrm{BmimBF}_{4}$, and $\mathrm{BmimPF}_{6}$ ionic liquids. The influence of the nature of IL anions, otherwise, demonstrated a distinct difference in titanium anodization for hydrophobic $\left(\mathrm{BmimNTf}_{2}, \mathrm{BmimBF}_{4}, \mathrm{BmimPF}_{6}\right)$ and hydrophilic $(\mathrm{BmimCl})$ ionic liquids. The alternating regions of polishing and pitting were observed on the titanium surface after anodization in the $\mathrm{BmimCl}$ medium.

On the other hand, the anodization of titanium in the mixture of $\mathrm{BmimCl}$ with propylene glycol (1:1) brought about the formation of surface titanium dioxide nanostructures (nanotubes), which was proved by cyclic voltammetry measurements [38].

The alloys based on titanium have also attracted growing attention owing to their application in medicine as biocompatible materials $[33,39]$. Titanium doped with $\mathrm{Al}$ and V is a widespread alloy used for prosthesis and implantable material fabrication [39]. 
The electropolishing of Ti-6Al-4V alloy in 1-buthyl-3-methylimidazolium chloride ionic liquid was studied [44]. Electropolishing of Ti-6Al-4V alloy used as a disk rotation electrode was carried out for various rotation speeds (50-200 rpm), voltages (15-60 V), and anodization times (0-8 $\mathrm{min})$. It was established that surface roughness effectively decreased from 0.682 to $0.311 \mathrm{~nm}$ for $8 \mathrm{~min}$ of anodization only at the $200 \mathrm{rpm}$ rotation speed and voltage of $30 \mathrm{~V}$. According to the AFM and SEM measurements, optimal parameters were recommended for the process, such as 6-7 min of anodization, high rotation speed (50-200 rpm), and average voltage (35-45 V) to achieve a metal surface of the required quality $[41,42]$. Otherwise, the roughness of the surface increases remarkably with time when the polishing of the Ti-6Al-4V alloy proceeds at a low rotation speed (50 rpm) and high voltage $(60 \mathrm{~V})$ [41].

The potentiostatic electropolishing of the same alloy was investigated in 1-ethyl-3methylimidazolium acetate $[41,42]$. It was found that the surface roughness indexes also decreased with polishing time. The optimal parameters of the process were found to be high rotation speed (150-200 rpm) and average voltages (35-45 V). The surface of the alloy after electropolishing for 6-8 min in IL found by EDX and AFM techniques was shown to be insignificantly depleted in $\mathrm{Al}$ and $\mathrm{V}$.

\subsection{Platinum}

Electrochemical polishing of $\mathrm{Pt}$ was studied in a series of ionic liquids based on the 1-butyl-3-methylimidazolium cation and various anions $\left(\mathrm{BmimBF}_{4}, \mathrm{BmimPF}_{6}\right.$, and BmimNTf 2 ) and 1-hexyl-3-methylimidazolium tetrafluoroborate $\left(\mathrm{HmimBF}_{4}\right)$ [38]. The polishing kinetics of $\mathrm{Pt}$ was calculated by measuring the change of the surface area of the electrode over time. The surface area of $\mathrm{Pt}(S)$ was found to decrease with time according to Equation (6).

$$
S=S_{\min }+\left(S_{\max }-S_{\min }\right) \exp \left(-k_{e f f} t\right)
$$

where $S_{\min }$ and $S_{\max }$ are the polished and unpolished surface area of $\mathrm{Pt}$, respectively; and $k_{\text {eff }}$ is the polishing rate constant observed.

The $\mathrm{Pt}$ area decrease is indicative of smoothing of the electrode surface. The rate of polishing was established to depend on the nature of the IL anion. The highest polishing rate was found for $\mathrm{BmimBF}_{4}$ and $\mathrm{HmimBF}_{4}$, exhibiting the optimal ratio between viscosity and electrical conductivity of IL. The change of the Pt surface roughness, $\Delta f$, was calculated according to Equation (7).

$$
\Delta f=\left[\left(S_{\max }-S_{\min }\right) / S_{\max }\right] \times 100 \%,
$$

It was found that $\Delta f$ values for $\mathrm{BmimBF}_{4}, \mathrm{BmimPF}_{6}, \mathrm{BmimNTf}_{2}$, and $\mathrm{HmimBF}_{4}$ $\left(20 \mathrm{~mA}, 25{ }^{\circ} \mathrm{C}\right)$ were $43 \%, 39 \%, 47 \%$, and $28 \%$, respectively [38].

\subsection{Copper}

Copper is known to be a less chemically active metal than other $3 d$-elements. Nevertheless, natural copper is also covered with thin invisible oxide films of $\mathrm{Cu}_{2} \mathrm{O}$ and $\mathrm{CuO}$. Electrochemical oxidation of copper in ionic liquids exhibits unusual features that are of great importance for the achievement of a metal surface of the highest smoothness [15]. The electropolishing of the majority of metals and alloys with oxidized surface begins with the dissolution of an oxide film, followed by the removal of metal atoms from the surface projections.

Electrochemical polishing of copper was studied in ethaline and IL based on the imidazolium cation- $\mathrm{BmimCl}$ [45-48]. Both electrolytes contain the chloride anion. The result of electropolishing of copper in ethaline carried out at $20^{\circ} \mathrm{C}$ is shown in Figure 6.

Copper electropolishing was found to depend on the nature of the solvent and experimental conditions (viscosity, concentration, temperature, etc.). The effects of cation and chloride anion concentrations and viscosity of the electrolyte after dilution with ethylene glycol were studied. The efficiency of the anodic dissolution of copper was due to solubility 
of the copper chloride compounds such as $\mathrm{CuCl}_{2}, \mathrm{CuCl}_{3}{ }^{-}$, or $\mathrm{CuCl}_{4}{ }^{-2}$. The temperature was established to influence the passivity role of the films of copper chloride complexes.

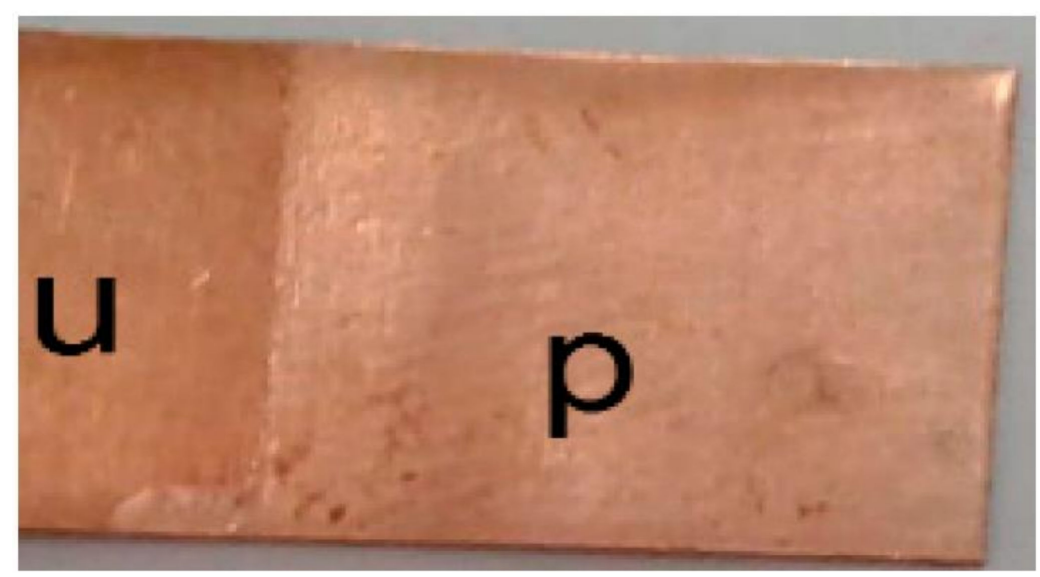

Figure 6. Photograph of the metal copper sheet before $(\mathrm{u})$ and after $(\mathrm{p})$ electropolishing in Ethaline at $0.18 \mathrm{~V}$ and $20^{\circ} \mathrm{C}$ for $10 \mathrm{~min}$ (reprinted with permission from ref. [45]; Copyright 2019 by the authors, licensee MDPI).

Effective smoothing of copper $(91.179 \%)$ was observed in ethaline [46]. The initial roughness of a $\mathrm{Cu}$ sample $(167.629 \mathrm{~nm})$ decreased to $82.610 \mathrm{~nm}$ after electropolishing in ethaline at $70{ }^{\circ} \mathrm{C}$ and $1.5 \mathrm{~V}$. The anodization of copper in ethaline occurred without hydrogen evolution to produce a mirror-like metal surface.

Electrochemical behavior of copper exhibiting various surface morphologies and compositions of oxide films was investigated gravimetrically under galvanostatic conditions in hydrophobic BmimNTf ${ }_{2}$ IL for natural surface oxidized, air-annealed, cathodically reduced, and cathodically deposited copper samples [15]. The air-annealed copper sheet with typical iridescences (Figure 7, bottom) exhibited a mirror-like surface after electropolishing in hydrophobic BmimNTf $\mathrm{IL}_{2}$. Figure 8 shows SEM images of the rough surface of copper obtained by cathodic deposition from $\mathrm{CuSO}_{4}$ water solution (Figure 8a) and after electropolishing in BmimNTf 2 IL (Figure 8b).

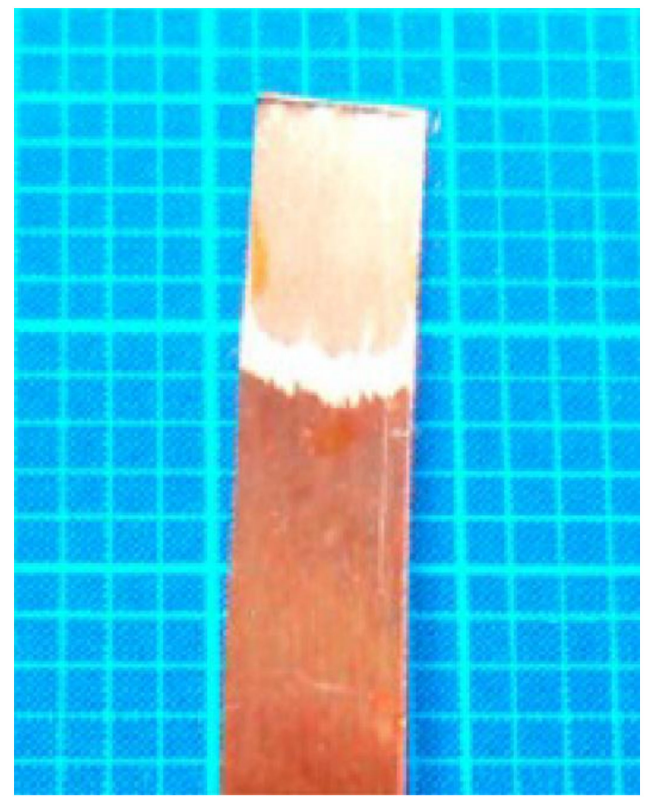

Figure 7. Photograph of the surface of the air-annealed copper electrode after electropolishing in BmimNTf $_{2}$ (reprinted with permission from ref. [15]; Copyright 2013 American Chemical Society). 

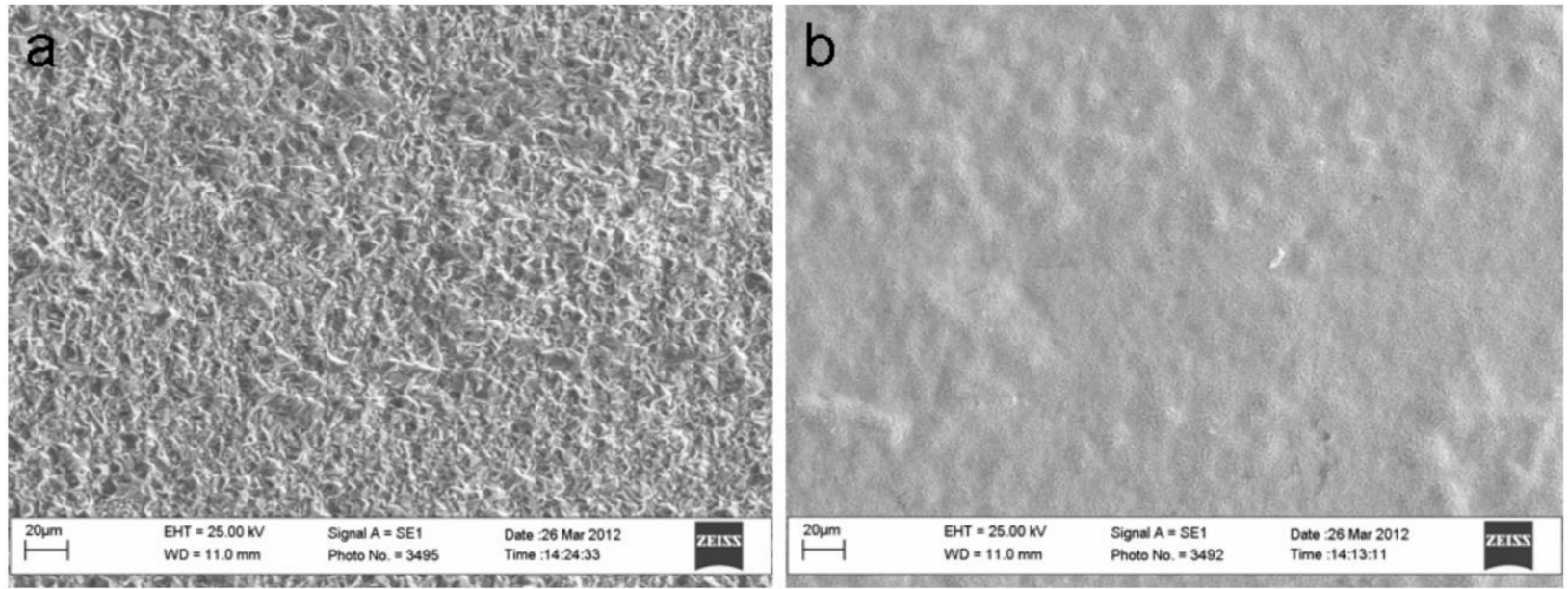

Figure 8. SEM images of the copper electrode obtained by cathodic deposition of copper from an aqueous $\mathrm{CuSO}_{4}$ solution before (a) and after (b) electropolishing in BmimNTf 2 (reprinted with permission from ref. [15]; Copyright 2013 American Chemical Society).

The data were presented by plots of the copper mass loss as functions of the quantity of electricity consumed. According to the results obtained, it was concluded that the dissolution of copper oxides had an electrochemical nature due to the one/two-electron Equations (8) and (9):

$$
\begin{gathered}
\mathrm{Cu}_{2} \mathrm{O}-1 \mathrm{e}^{-} \rightarrow \mathrm{Cu}^{+}+\mathrm{CuO} \\
\mathrm{CuO}-2 \mathrm{e}^{-} \rightarrow \mathrm{Cu}^{+2}+\mathrm{O}_{\mathrm{ads}} \\
\mathrm{Cu}-1 \mathrm{e}^{-} \rightarrow \mathrm{Cu}^{+}
\end{gathered}
$$

Electrochemical smoothing of copper asperities to obtain a mirror-like surface (Figure 7) was found to occur owing to Equation (10) in hydrophobic BmimNTf $\mathrm{IL}_{2} \mathrm{IL}$ after removal of the surface oxides. It was found that the efficiency of copper polishing increased in water-saturated hydrophobic IL. This means that Equation (10) occurs primarily on the salient sites rather than on the recesses and pits of the copper surface (Figure 9), providing rapid and economic dissolution of the metal.

\section{water-saturated Bmim $\mathrm{NTf}_{2}$}

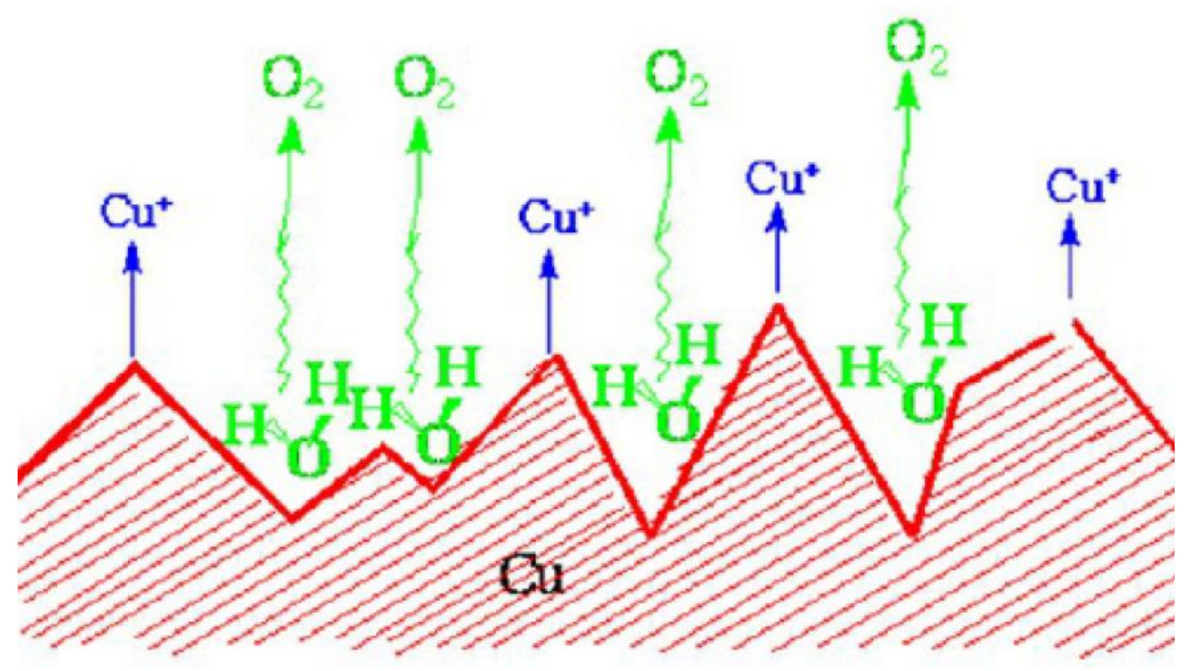

Figure 9. The mechanism of copper electropolishing in water-saturated hydrophobic BmimNTf $\mathrm{IL}_{2}$ (reprinted with permission from ref. [15]; Copyright 2013 American Chemical Society). 
The copper electropolishing in BmimNTf ${ }_{2}$ seemed to depend on the composition and properties of the solvent. A distinct difference was observed for electropolishing of the oxidized and oxygen-free surface of the copper electrode. The authors showed that the dissolution of the copper oxide films occurred in hydrophobic BmimNTf ${ }_{2}$ ionic liquid rather than in hydrophilic $\mathrm{BmimCl}$ [15].

\subsection{Aluminum}

A smooth surface of aluminum was obtained by electropolishing in an ionic liquid based on the mixture of anhydrous aluminum chloride with trimethylamine hydrochloride in the absence of oxygen (Figure 10) [46,48-51]. Figure 10 demonstrates the surface of $\mathrm{Al}$ before polishing ( $\mathrm{a}$ and $\mathrm{c}$ ) and after electrochemical treatment in IL (b and $\mathrm{d}$ ). The electropolished sample exhibits the high reflectivity of the mirror-like surface of the metal (b), which reflects an image located in front of it. The average roughness of the Al surface diminishes from 15.2 to $2.58 \mathrm{~nm}$ after electropolishing in IL. It was found also that the oxygen content on the $\mathrm{Al}$ surface decreased from 6.49 to $1.5 \mathrm{wt} \%$ after electropolishing, whereas no Al depletion was observed.
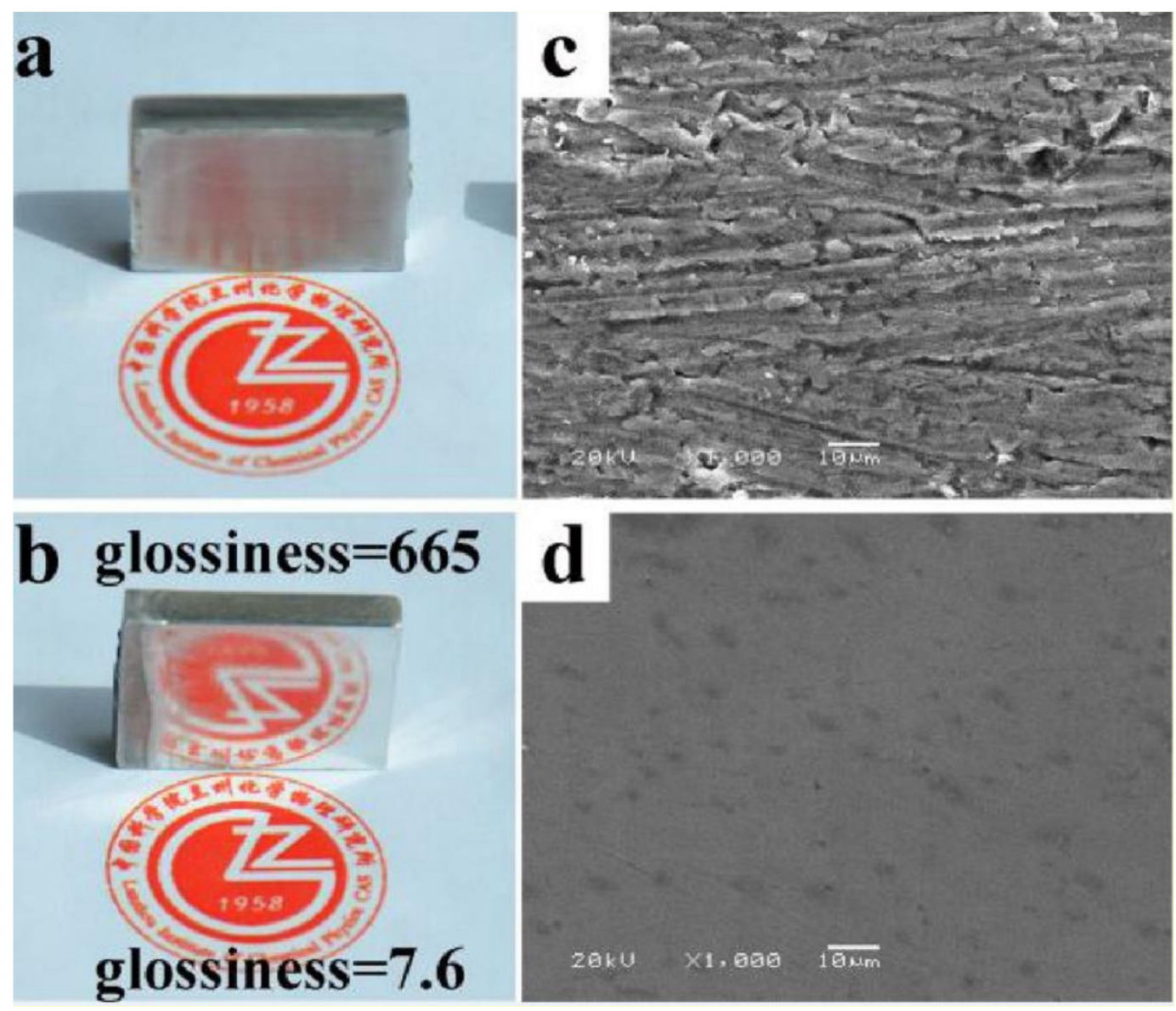

Figure 10. Photographs $(\mathbf{a}, \mathbf{b})$ and SEM images $(\mathbf{c}, \mathbf{d})$ of the Al sample before $(\mathbf{a}, \mathbf{c})$ and after $(\mathbf{b}, \mathbf{d})$ electropolishing in an anhydrous aluminum chloride-trimethylamine hydrochloride mixture (reprinted with permission from ref. [48]; Copyright 2017 Elsevier).

The authors noted that the glossiness of the original surface of $\mathrm{Al}(7.6)$ increased to 665 [48] after electropolishing of the sample in a mixture of anhydrous aluminum chloride with trimethylamine hydrochloride.

Electropolishing of $\mathrm{Al}$ was also studied in ethaline [46,51]. The surface of $\mathrm{Al}$ polished in ethaline demonstrated high optical reflectivity (4.5) [46]. Authors compared the results of electropolishing of aluminum in phosphoric acid and acid-free IL. It was established that $\mathrm{Al}$ roughness before and after electropolishing in ethaline decreased from 159.310 to 
$26.649 \mathrm{~nm}$, respectively. The smoothing efficiencies were found to comprise about $83 \%$ in ethaline and $39 \%$ in $1 \mathrm{M}$ phosphoric acid [46,51]. The authors claimed that optimal conditions for electropolishing of aluminum in ethaline were $2 \mathrm{~V}$ for $900 \mathrm{~s}$.

The surface morphologies of the high-purity aluminum samples before and after anodization were depicted for electrochemical etching in a deep eutectic solvent (Figure 11) [51]. Although the electropolishing rate of aluminum was higher in a phosphoric acid medium $(50.8 \mu \mathrm{g} / \mathrm{s})$ (it was $43.7 \mu \mathrm{g} / \mathrm{s}$ in ionic liquid), the smoothing efficiency was established by AFM calculations to be significantly higher in the ionic liquid (roughness average $\mathrm{Ra}=26 \pm 2 \mathrm{~nm}$ ) than in phosphoric acid solutions ( $\mathrm{Ra}=97 \pm 6 \mathrm{~nm})$.
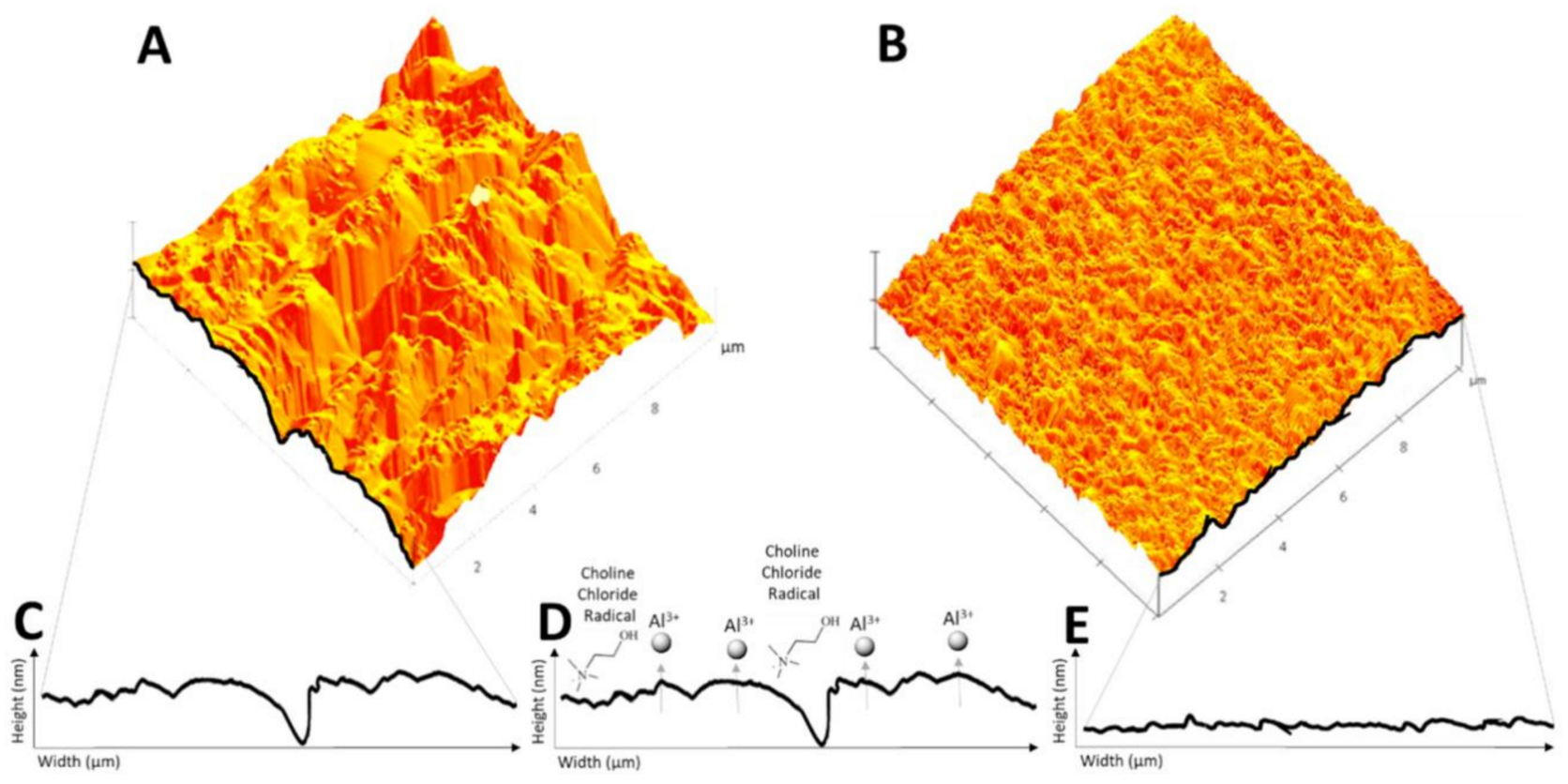

Figure 11. Schematic conceptualization of anodic leveling of the aluminum surface via AFM at different phases: before electropolishing (A), and after electropolishing (B) in ethaline; representative 2D surface profiles depicted before (C), during (D), and after (E) anodization (reprinted with permission from ref. [51]; Copyright 2020 by the authors, licensee MDPI).

This makes the deep eutectic medium more preferable if the smoothing efficiency is the main requirement for electropolishing of high-purity aluminum.

\subsection{Uranium}

The polishing of the surface of radioactive metals reveals some difficulties because of the high radioactivity. The most secure way to smoothen a surface of radioactive metals is electropolishing in ILs to prevent the formation of radioactive aerosols.

Electropolishing of metallic uranium was carried out in 1-ethyl-3-methylimidazolium chloride ionic liquid in the presence of $\mathrm{AlCl}_{3}$ [52]. Uranium was found to be electrochemically oxidized with $\mathrm{U}^{3+}$ formation. Diffusion of $\mathrm{U}^{3+}$ ions through the diffusion layer away from the anode determines the dissolution rate of uranium. A burgundy-colored film was observed on the surface of uranium by exposing the electrode to IL for 2 min at $6 \mathrm{~mA} \mathrm{~cm}^{-2}$

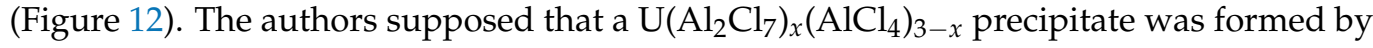
electropolishing of the metal. 


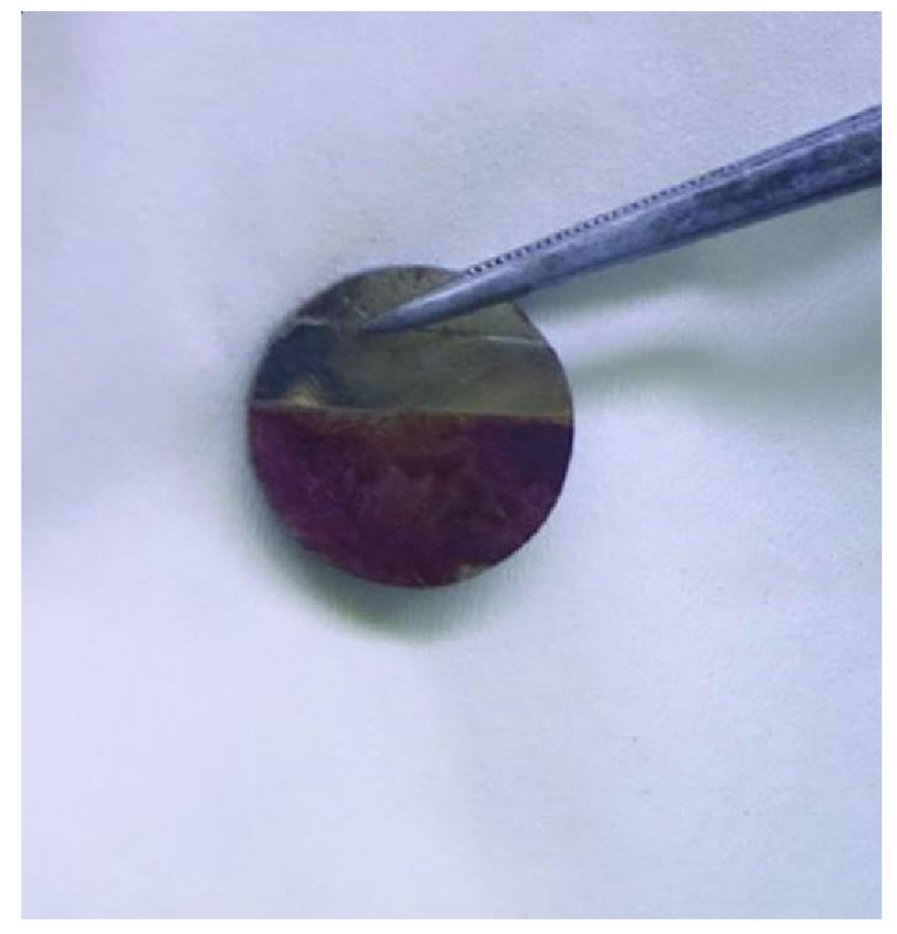

Figure 12. Photograph of a burgundy film on the surface of uranium after anodization in a 1-ethyl-3methylimidazolium chloride- $\mathrm{AlCl}_{3}$ mixture (1:2 molar ratio) at $6 \mathrm{~mA} \mathrm{~cm}{ }^{-2}$ for $2 \mathrm{~min}$ (reprinted with permission from ref. [52]; Copyright 2018 the author(s), published by The Electrochemical Society).

\subsection{Tin}

Ionic liquids based on the pyrrolidinium cation were also successively used for electropolishing of tin [53-55]. 1-Butyl-1-methylpyrrolidinium bis(trifluoromethylsulfonyl) imide (BMPNTf ${ }_{2}$ ) was tested as an electrolyte for anodic dissolution of tin. The authors studied the behavior of an $\mathrm{Sn}$ electrode under various experimental conditions. It is seen in Figure 13 that some scratches on the tin surface that resulted from the mechanical abrasion of the sample disappear after potentiostatic anodization at $0.1 \mathrm{~V}$. The decrease in the roughness of the electrode from 283 to $79 \mathrm{~nm}$ after anodization in $\mathrm{BMPNTf}_{2}$ leads to the shiny surface of tin due to the viscous layer formation on the metal [53].
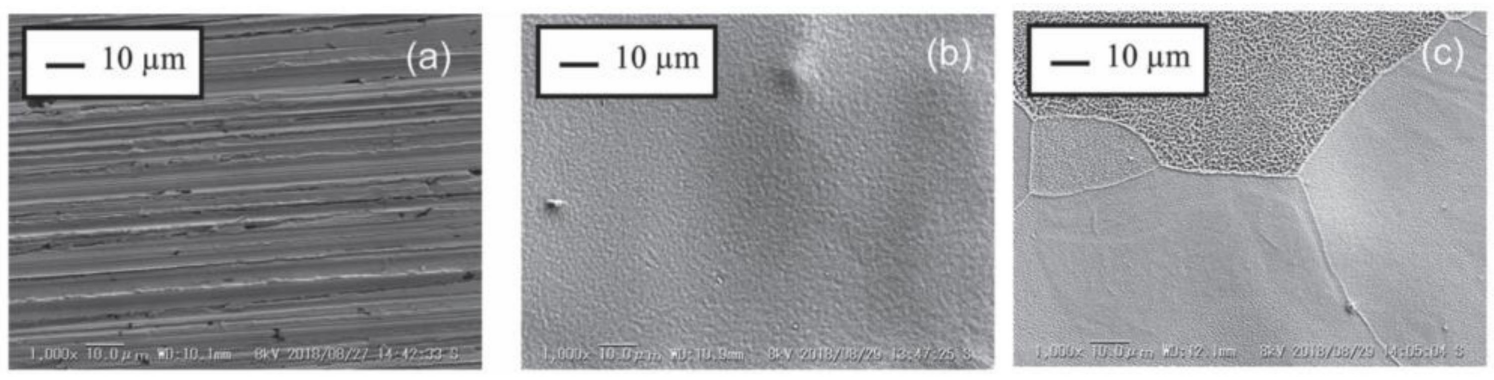

Figure 13. SEM images of an Sn electrode before $(\mathbf{a})$ and after $(\mathbf{b}, \mathbf{c})$ potentiostatic anodization in BMPNTf 2 at $0.1 \mathrm{~V}\left(\mathrm{Ag} / \mathrm{Ag}^{+}\right)$ with stirring at 1200 and $1500 \mathrm{rpm}\left(25^{\circ} \mathrm{C}\right)$; current density $14.3(\mathbf{b})$ and $29.1 \mathrm{C} \mathrm{cm}^{-2}$ (c) (reprinted with permission from ref. [53]; Copyright 2021 the author(s), published on behalf of The Electrochemical Society by IOP Publishing).

The same polishing effect was observed for the galvanostatic anodization of tin $\left(0.5 \mathrm{~mA} \mathrm{~cm}^{-2}\right)$. The role of the viscous layer formation in the surface finishing of the metal was established [53-55]. The $S n(2+)$ diffusion through the viscous layer near the electrode was found to be the rate-determining stage of electropolishing. 


\subsection{Nickel}

The data on electropolishing of nickel were obtained in a mixture of choline chloride with ethylene glycol (1:2) [56-63]. The nickel finishing was conducted at the optimum voltage of $3.75 \mathrm{~V}$ for $900 \mathrm{~s}$ at $70{ }^{\circ} \mathrm{C}$. The average roughness of nickel was found to decrease from 138.408 to $28.640 \mathrm{~nm}$ to form a smoothed surface of the sample in ethaline [56].

The electrochemical behavior of nickel metal of high purity $(>99.9 \%)$ in the mixture of ethylene glycol and vitamin-B4 (2:1, respectively) at $70{ }^{\circ} \mathrm{C}$ was studied by means of chronoamperometry and voltammetry [62]. Calculations via atomic force microscopy (AFM) gave additional information regarding the surface morphology of the samples before and after anodization in the eutectic ionic liquid (Figure 14).
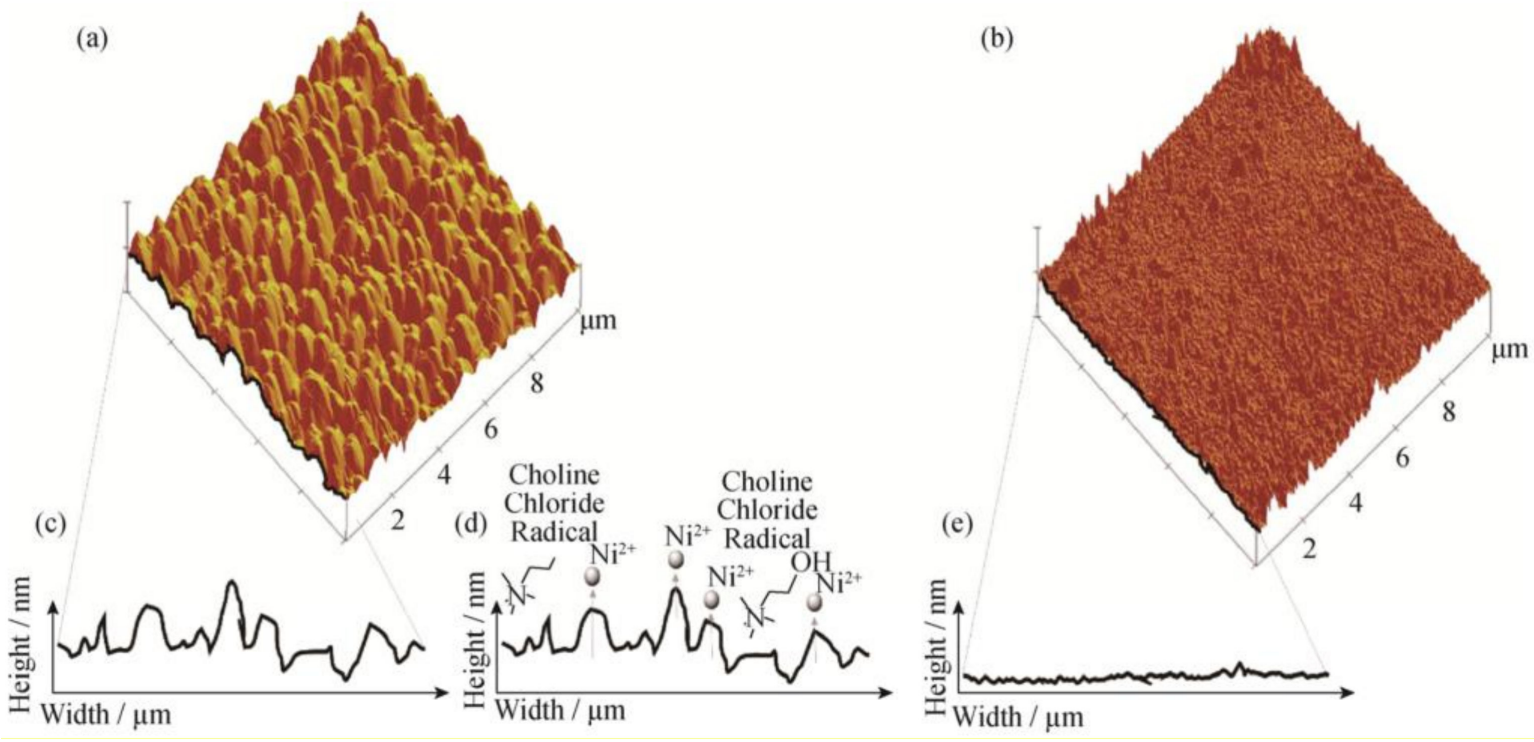

Figure 14. Schematic explanation of anodic leveling of nickel via AFM before electropolishing (a), and after electropolishing treatments (b), with representative 2D surface profiles depicted before the experiment (c), during the experiment (d), and after treatments (e). Vertical height scales are the same across all micrographs and profiles (reprinted with permission from ref. [62]; Copyright (C 2019, University of Science and Technology Beijing and Springer-Verlag GmbH Germany, part of Springer Nature).

According to the data obtained, the samples of nickel were electropolished to be mirrorlike, from $R_{\mathrm{q}}$ of $138.41 \mathrm{~nm}$ to $R_{\mathrm{q}}$ of $18.64 \mathrm{~nm}$ with a smoothing efficiency of $79.308 \%$ [62]. The authors assumed that choline cations undergo one-electron reduction on the cathode to choline radicals, followed by decomposition to form triethylamine and ethanol radicals. It was concluded that the rate of electropolishing did result in a statistically significant improvement in the surface roughness of high-purity nickel metal.

The experiments revealed also that the high current leads to pitting, and high voltage yields the oxide film formation on the nickel anode. It was found that the result of the anodization of high purity nickel metal depended on the optimal relationship between the voltage and current (Figure 15) [62].

The smoothing of the nickel surface by electropolishing in ethaline was found to bring about the improvement of anticorrosion properties [63]. The enhancement in the potential of the nickel electrode in ethaline was shown to improve the surface morphology. It was concluded that the more uniform and smoother the nickel surface, the higher was its corrosion resistance [63]. 


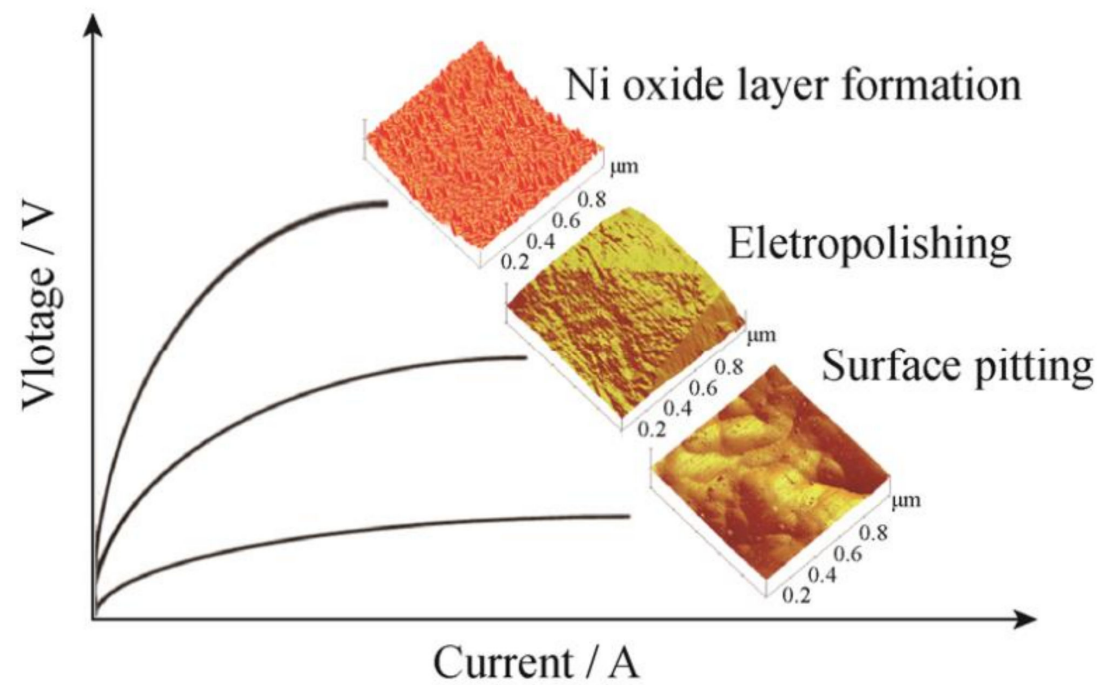

Figure 15. Schematic diagram describing the optimal relationship between the voltage and current for nickel electropolishing, and examples of resulting $10 \mu \mathrm{m} \times 10 \mu \mathrm{m}$ surface characteristics via AFM micrographs (reprinted with permission from ref. [62]; Copyright (C) 2019, University of Science and Technology Beijing and Springer-Verlag GmbH Germany, part of Springer Nature).

\subsection{Silver}

A mixture of choline chloride with ethylene glycol was used also for electropolishing of silver to obtain the smoothed surface required for manufacturing integrated circuit devices $[56,64]$. According to AFM data, a decrease in the roughness was observed after electropolishing in ethaline (Figure 16). The $R_{\mathrm{a}}$ calculated values diminished from 181.450 to $31.017 \mathrm{~nm}$ after anodization of the sample.

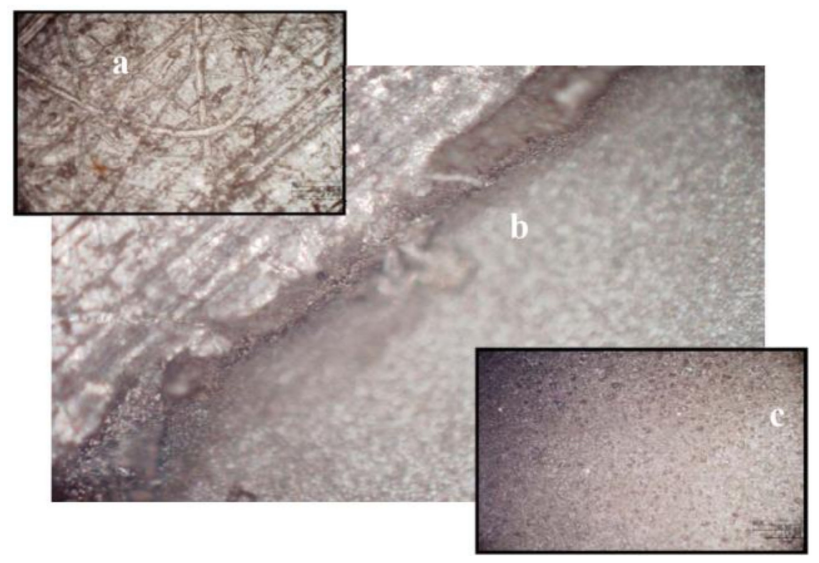

Figure 16. Digital microscopy of silver before electropolishing (a), along the electropolishing divide (b) and after electropolishing in ethaline (c) (reprinted with permission from ref. [56]; Copyright 2010 The Electrochemical Society).

The optimum voltage and current density for the effective electropolishing of metal silver were determined to be $3.75 \mathrm{~V}$ and $0.064 \mathrm{~A} / \mathrm{cm}^{2}$ [64].

\subsection{Niobium}

Metallic niobium with a smooth mirror-like surface is required for the fabrication of the cavities of superconducting radio frequency accelerators [65-70]. Niobium is an expensive metal to be polished in aqueous acid solutions. Ionic liquid based on choline chloride, ethylene glycol, urea, and ammonium fluoride (2:2:2:1 molar ratio, respectively) was successfully used also for electropolishing of niobium [65-68,70]. A shiny surface of niobium was obtained by electropolishing at $70{ }^{\circ} \mathrm{C}$ and voltage of $8.0 \mathrm{~V}$ for $900 \mathrm{~s}$. According to AFM data, the 
initial surface roughness of the niobium sample was reduced by more than $95 \%$. SEM images (Figure 17) showed the change of the as-received sample of niobium (Figure 17a) after electropolishing in the above mixture (Figure 17b). The average niobium surface roughness was found to diminish after electropolishing in acid-free IL below $22 \mathrm{~nm}$.

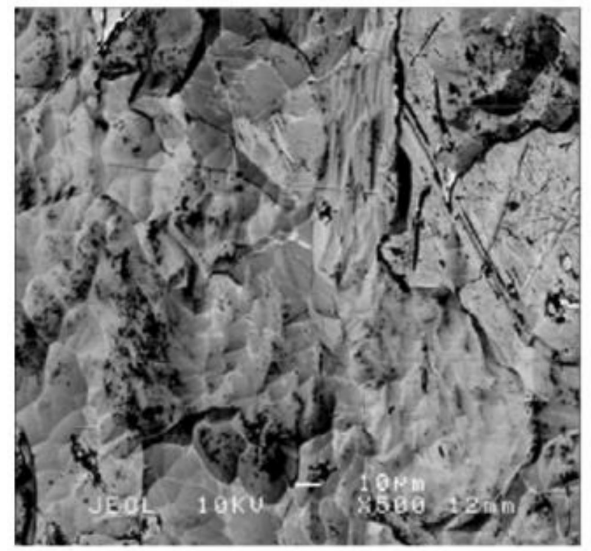

(a)

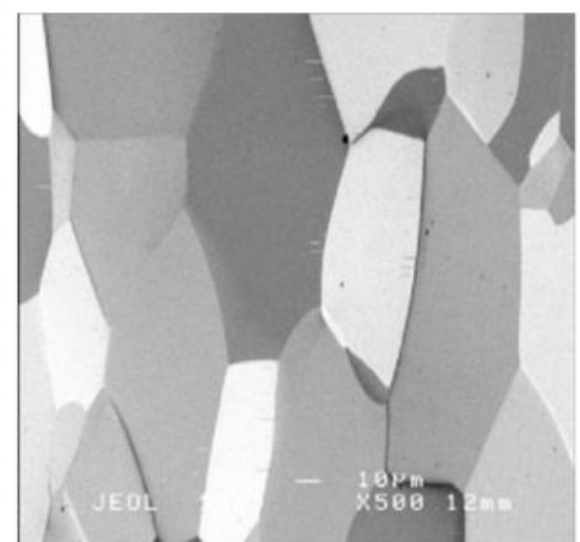

(b)

Figure 17. SEM views of the initial (a) and IL-polished (b) niobium sheet (reprinted with permission from ref. [65]; Copyright 2010 The Electrochemical Society).

Electrochemical impedance spectroscopy was used to study the mechanism of the $\mathrm{Nb}$ electropolishing in deep eutectic solvents [70]. The electropolishing of $\mathrm{Nb}$ was suggested to be in accordance with a compact salt film mechanism. The applied potentials and temperature were found to affect the result of electropolishing of metallic niobium. Physical and chemical properties of the $\mathrm{Nb}$ surface (crystal structure, morphology, composition) were investigated also, before and after electropolishing, by XRD, XPS, and SEM techniques. The mirrorlike surface of metallic $\mathrm{Nb}$ was shown to be formed from the electropolishing of $\mathrm{Nb}$ in an ionic liquid (Figure 18). The stretches and irregular defects (average roughness is $538 \mathrm{~nm}$ ) observed on the surface of the $\mathrm{Nb}$ sample are seen to disappear after electrochemical polishing $\left(R_{\mathrm{a}}=105 \mathrm{~nm}\right)$, thus demonstrating the high efficiency of the electrochemical finishing.

The electrochemical kinetics of electropolishing of metallic niobium as a disc rotating electrode revealed the significant role of a $\mathrm{NbO}_{x}$ film, the thickness of which is independent of temperature but decreases with the increase in the rotation rate.
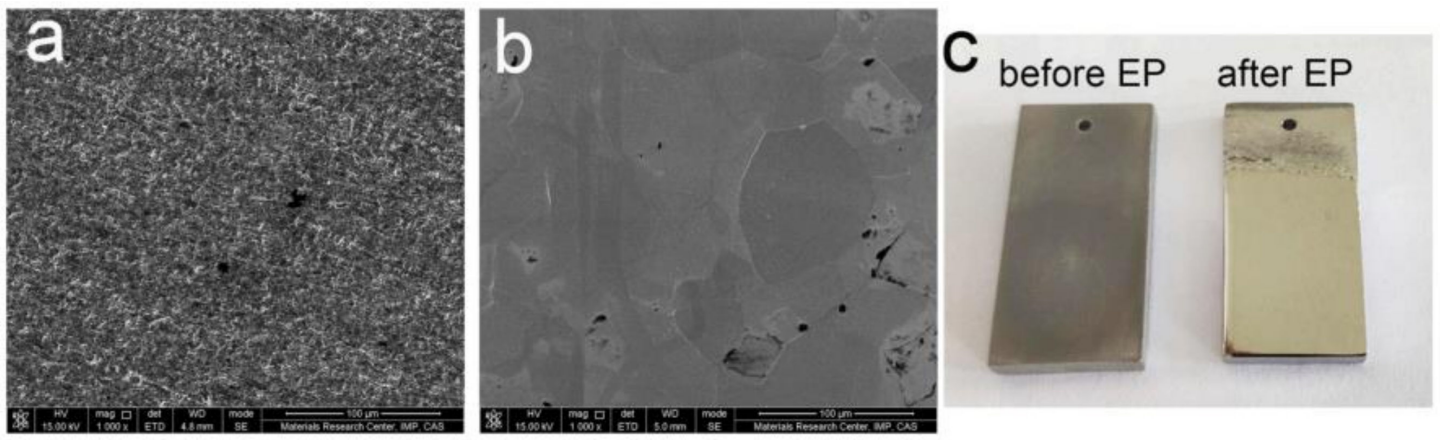

Figure 18. Surface micrographs of $\mathrm{Nb}$ samples: before (a) and after (b) electropolishing; optical picture (c). (Reprinted with permission from ref. [70]; Copyright 2021 Elsevier.) 


\subsection{Alloys}

Ethaline demonstrated high efficiency in electropolishing of alloys based on $d$-metals, which are of particular importance as biocompatible materials for total joint replacement in medicine [28].

Electropolishing of CMSX4 and CMSX10N superalloys based on nickel doped with Re, $\mathrm{W}, \mathrm{Ta}, \mathrm{Al}$, Ti and other metals was carried out in ethaline $200 \mathrm{IL}$ to remove a surface oxide scale from single crystal aerospace castings [60]. The anodization of the superalloys for 30-60 min resulted in reduced surface roughness to form a lustrous workpiece (Figure 19).

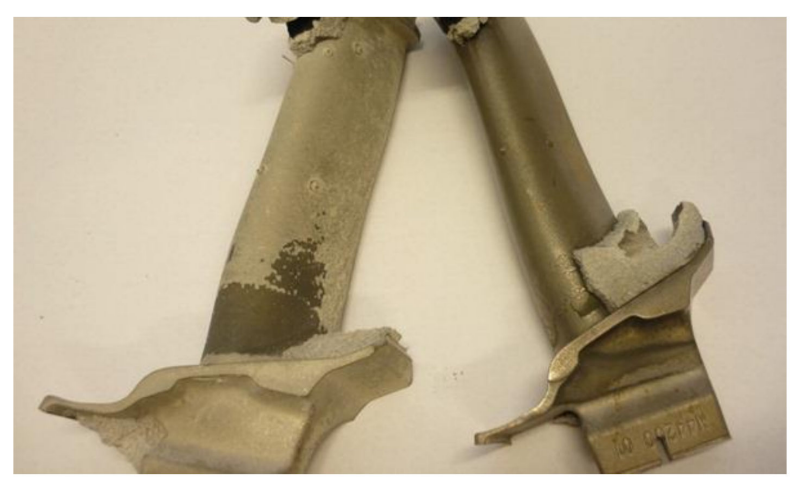

Figure 19. A workpiece of nickel-based superalloy before (left) and after (right) electropolishing in ethaline 200 (reprinted with permission from ref. [60]; Copyright 2013 the author(s), published by Informa UK Limited, trading as Taylor \& Francis Group).

The copper- [71] and titanium-based [33] alloys were also electropolished in ethaline. The electropolishing of bronzes of the types $\mathrm{AMPCO}^{\circledR} 22$ (containing $\mathrm{Al}$ and $\mathrm{Fe}$ ) and $\mathrm{AMPCO}^{\circledR} 712$ (containing $\mathrm{Sn}, \mathrm{Ni}, \mathrm{Pb}$, and $\mathrm{Zn}$ ) were studied in ethaline at $25^{\circ} \mathrm{C}$ and $2.5 \mathrm{~V}$ of the anodic potential (vs. the Ag pseudo-reference electrode). Potentiostatic anodization of both kinds of bronzes was established to bring about the improvement of the surface morphology. The surface copper content increased after electropolishing from $72.41 \%$ to $81.87 \%$ for $\mathrm{AMPCO}^{\circledR} 22$ and from $81.83 \%$ to $83.04 \%$ for $\mathrm{AMPCO}^{\circledR} 712$, likely due to exhaustion of $\mathrm{Al}$ (from $10.05 \%$ to $8.97 \%$ ) and $\mathrm{Sn}$ (from $12.35 \%$ to $8.58 \%$ ), respectively. The improvement of the surface morphology of the above bronzes after anodization in ehaline ( $R_{\mathrm{q}}$ from 626.8 to $135.3 \mathrm{~nm}$ and from 454.0 to $179.4 \mathrm{~nm}$ for $\mathrm{AMPCO}^{\circledR} 22$ and $\mathrm{AMPCO}^{\circledR} 712$, respectively) resulted in the anodic potential shift for both alloys [71].

The electrochemical polishing of titanium alloy (98.2 (Ti), $0.3(\mathrm{Al})$, and $1.5 \%(\mathrm{C})$ ) in ethaline resulted in the formation of the specific surface patterns with nanoscale irregularities enriched with oxygen and carbon [33]. The wettability of the alloy surface was used to define the surface roughness (Figure 20). The surface hydrophobicity of the Ti-based alloy was found to increase nonmonotonically with time after electropolishing in ethaline due to respective changes in the surface roughness. The average roughness coefficients $\left(R_{\mathrm{a}}\right)$ seemed to diminish in general after electropolishing of the Ti-alloy. However, the increase in the processing time resulted in the marked decrease in $R_{\mathrm{a}}$.

The surfaces of the alloys based on $\mathrm{Zr}_{2} \mathrm{Ni}$ doped by silicon ( 3 at.\%) in the amorphous and crystalline states were electrochemically polished in the ionic liquid BmimNTf $\mathrm{B}_{2}$ in the galvanostatic regime [72]. It was found that a much more uniform distribution of the nanosized fragments could be obtained (and a more uniform surface polishing) in the case of amorphous $\mathrm{Zr}_{67} \mathrm{Ni}_{30} \mathrm{Si}_{3}$ alloy. 


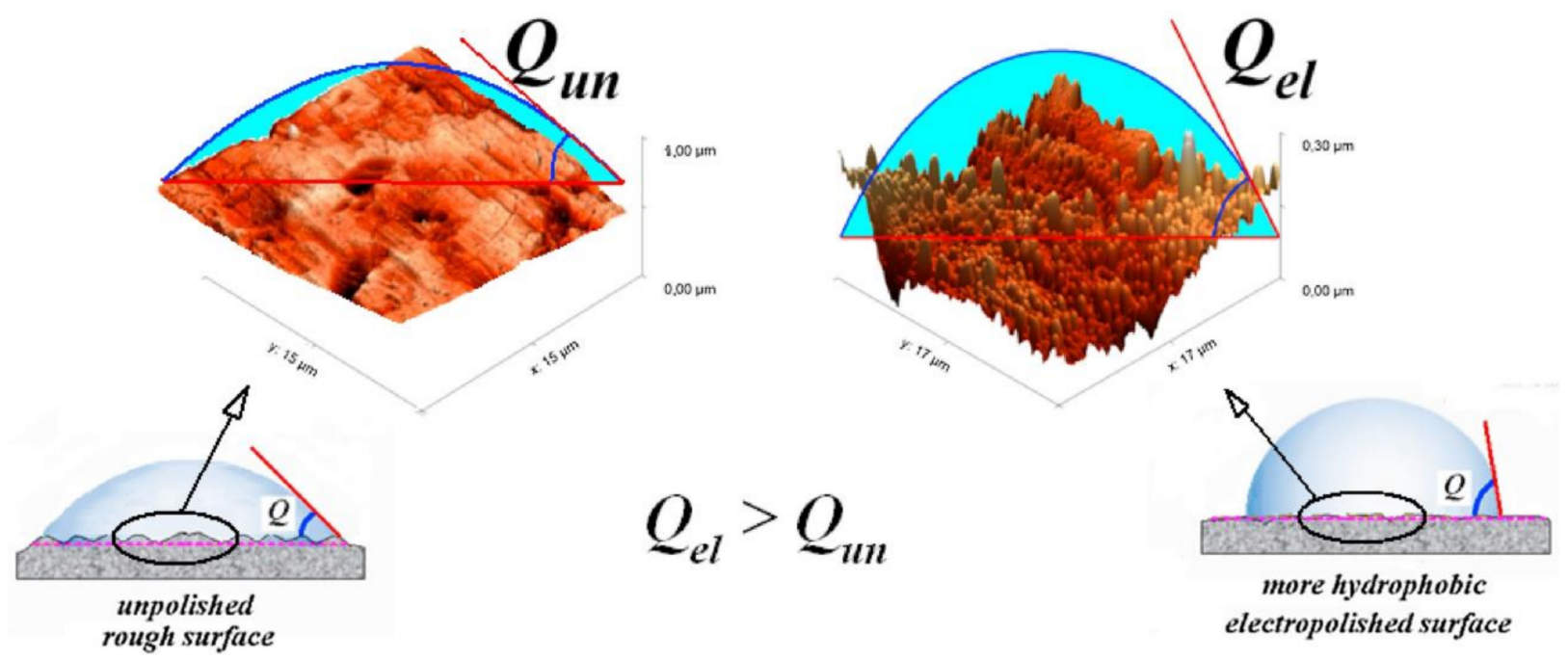

Figure 20. Schematic representation of the effect of the surface morphology of unpolished and electropolished surface of Ti-based alloy on liquid spreading (reprinted with permission from ref. [33]; Copyright 2021 Elsevier).

\section{Conclusions}

In recent years, ionic liquids based on organic cations have effectively displaced acidic electrolytes in the processes of metal and alloy finishing due to their clear advantages. The use of ionic liquids for electrochemical treatment of metals gives an opportunity to delicately remove the superficial roughness. Electropolishing of metals in ionic liquids provides benign conditions for metal finish to obtain the required quality of the surface. The wide electrochemical window of ionic liquids allows excluding side reactions with electrolyte participation. Anodization of metals in acid-free ionic liquids often leads to smoothing the metal surface and obtaining mirror-like metal surfaces rather than etching and pitting. There are several barriers to commercialization of ionic liquids for electropolishing application, including [73]:

- A rather high cost of the chemicals used to prepare ionic liquids;

- The need to establish compliance with existing and planned environmental regulations;

- The processes are not optimized.

However, these are temporary barriers that can be overcome in the near future, taking into account the unique advantages of these benign electrolytes in this particular application as well as the economy of materials that are otherwise lost at scale in the case of mechanical polishing.

Author Contributions: All authors declare equal participation in this work. O.L.-Draft preparation, D.K.-Draft preparation, A.Z.-Final version preparation, L.K.-Editing and proof-reading. All authors have read and agreed to the published version of the manuscript.

Funding: This research was funded by Ministry of Science and Higher Education of the Russian Federation in the framework of Increase Competitiveness Program of NUST «MISiS», grant number K2-2020-031.

Institutional Review Board Statement: Not applicable.

Informed Consent Statement: Not applicable.

Data Availability Statement: Not applicable.

Acknowledgments: Authors thank Irina Balykova for the assistance provided in the search of some references and DOI.

Conflicts of Interest: The authors declare no conflict of interest. 


\section{References}

1. Han, W.; Fang, F. Fundamental Aspects and Recent Developments in Electropolishing. Int. J. Mach. Tools Manuf. 2019, 139, 1-23. [CrossRef]

2. Abbott, A.P.; Frisch, G.; Hartley, J.; Karim, W.O.; Ryder, K.S. Anodic Dissolution of Metals in Ionic Liquids. Prog. Nat. Sci. Mater. Int. 2015, 25, 595-602. [CrossRef]

3. Yang, G.; Wang, B.; Tawfiq, K.; Wei, H.; Zhou, S.; Chen, G. Electropolishing of Surfaces: Theory and Applications. Surf. Eng. 2017, 33, 149-166. [CrossRef]

4. Landolt, D. Fundamental Aspects of Electropolishing. Electrochim. Acta 1987, 32, 1-11. [CrossRef]

5. Datta, M.; Landolt, D. Fundamental Aspects and Applications of Electrochemical Microfabrication. Electrochim. Acta 2000, 45, 2535-2558. [CrossRef]

6. Hensel, K.B. Electropolishing. Met. Finish. 2000, 98, 440-448. [CrossRef]

7. Łyczkowska-Widłak, E.; Lochyński, P.; Nawrat, G. Electrochemical Polishing of Austenitic Stainless Steels. Materials 2020, 13, 2557. [CrossRef]

8. Chemical and Electrolytic Polishing. Metallography and Microstructures; Vander Voort, G.F., Ed.; ASM International: Novelty, OH, USA, 2004; pp. 281-293. ISBN 978-1-62708-177-1.

9. Lei, Z.; Chen, B.; Koo, Y.-M.; MacFarlane, D.R. Introduction: Ionic Liquids. Chem. Rev. 2017, 117, 6633-6635. [CrossRef] [PubMed]

10. Tiago, G.A.O.; Matias, I.A.S.; Ribeiro, A.P.C.; Martins, L.M.D.R.S. Application of Ionic Liquids in Electrochemistry-Recent Advances. Molecules 2020, 25, 5812. [CrossRef] [PubMed]

11. Van Ginneken, B.; Stavridi, M.; Koenderink, J.J. Diffuse and Specular Reflectance from Rough Surfaces. Appl. Opt. 1998, 37, 130-139. [CrossRef]

12. Kerker, M. The Scattering of Light and Other Electromagnetic Radiation; Physical Chemistry; Academic Press: New York, NY, USA, 1969; ISBN 978-0-12-404550-7.

13. Lugolole, R.; Obwoya, S.K. The Effect of Thickness of Aluminium Films on Optical Reflectance. J. Ceram. 2015, 2015, 213635. [CrossRef]

14. Hass, G.; Scott, N.W. On the Structure and Properties of Some Metal and Metal Oxide Films. J. Phys. Radium 1950, 11, 394-402. [CrossRef]

15. Lebedeva, O.; Dzhungurova, G.; Zakharov, A.; Kultin, D.; Kustov, L.; Krasovskii, V.; Kalmykov, K.; Dunaev, S. Surface State of Sacrificial Copper Electrode by Electropolishing in Hydrophobic Ionic Liquid 1-Butyl-3-Methylimidazolium Bis(Trifluoromethylsulfonyl)Imide. ACS Appl. Mater. Interfaces 2013, 5, 10551-10558. [CrossRef]

16. England, W.A.; Jenny, S.N.; Greenhalgh, D.A. Chromium Oxide Film Thickness Measurements Using Spontaneous Raman Scattering. J. Raman Spectrosc. 1984, 15, 156-159. [CrossRef]

17. Mallikarjuna Reddy, A.; Sivasankar Reddy, A.; Sreedhara Reddy, P. Thickness Dependent Properties of Nickel Oxide Thin Films Deposited by Dc Reactive Magnetron Sputtering. Vacuum 2011, 85, 949-954. [CrossRef]

18. Pouilleau, J.; Devilliers, D.; Garrido, F.; Durand-Vidal, S.; Mahé, E. Structure and Composition of Passive Titanium Oxide Films. Mater. Sci. Eng. B 1997, 47, 235-243. [CrossRef]

19. Sittig, C.; Textor, M.; Spencer, N.D.; Wieland, M.; Vallotton, P.-H. Surface Characterization of Implant Materials Ti, Ti-6Al-7Nb and Ti-6Al-4V with Different Pretreatments. J. Mater. Sci. Mater. Med. 1999, 10, 35-46. [CrossRef]

20. Bianchi, G.; Cerqumi, A.; Mazza, F.; Torchio, S. Chemical Etching and Pitting of Stainless Steel. Corros. Sci. 1970, 10, 19-27. [CrossRef]

21. Singh, S.K.; Savoy, A.W. Ionic Liquids Synthesis and Applications: An Overview. J. Mol. Liq. 2020, 297, 112038. [CrossRef]

22. Rogers, R.D. CHEMISTRY: Ionic Liquids—Solvents of the Future? Science 2003, 302, 792-793. [CrossRef] [PubMed]

23. Earle, M.J.; Seddon, K.R. Ionic Liquids. Green Solvents for the Future. Pure Appl. Chem. 2000, 72, 1391-1398. [CrossRef]

24. Huo, J.; Solanki, R.; McAndrew, J. Electrochemical Polishing of Copper for Microelectronic Applications. Surf. Eng. 2003, 19, 11-16. [CrossRef]

25. Jayakrishna, K.; Kar, V.R.; Sultan, M.T.H.; Rajesh, M. Materials selection for aerospace components. In Sustainable Composites for Aerospace Applications; Elsevier: Amsterdam, The Netherlands, 2018; pp. 1-18. ISBN 978-0-08-102131-6.

26. Artini, C. (Ed.) Alloys and Intermetallic Compounds: From Modeling to Engineering, 1st ed.; A Science Publishers Book; Taylor \& Francis Group; CRC Press: Boca Raton, FL, USA, 2017; ISBN 978-1-315-15161-8.

27. Lappin, D.; Mohammadi, A.R.; Takahata, K. An Experimental Study of Electrochemical Polishing for Micro-Electro-DischargeMachined Stainless-Steel Stents. J. Mater. Sci. Mater. Med. 2012, 23, 349-356. [CrossRef] [PubMed]

28. Abdel-Fattah, T.M.; Loftis, J.D.; Mahapatro, A. Nanoscale Surface Pretreatment of Biomedical Co-Cr Alloy. J. Surf. Interfaces Mater. 2015, 3, 67-74. [CrossRef]

29. Williams, D.F. On the Mechanisms of Biocompatibility. Biomaterials 2008, 29, 2941-2953. [CrossRef]

30. Larsson, C.; Thomsen, P.; Lausmaa, J.; Rodahl, M.; Kasemo, B.; Ericson, L.E. Bone Response to Surface Modified Titanium Implants: Studies on Electropolished Implants with Different Oxide Thicknesses and Morphology. Biomaterials 1994, 15, 1062-1074. [CrossRef]

31. Raval, A.; Choubey, A.; Engineer, C.; Kothwala, D. Development and Assessment of 316LVM Cardiovascular Stents. Title Mater. Sci. Eng. A 2004, 386, 331-343. [CrossRef]

32. Larsson, C.; Thomsen, P.; Aronsson, B.-O.; Rodahl, M.; Lausmaa, J.; Kasemo, B.; Ericson, L.E. Bone Response to Surface-Modified Titanium Implants: Studies on the Early Tissue Response to Machined and Electropolished Implants with Different Oxide Thicknesses. Biomaterials 1996, 17, 605-616. [CrossRef] 
33. Kityk, A.; Protsenko, V.; Danilov, F.; Pavlik, V.; Hnatko, M.; Šoltýs, J. Enhancement of the Surface Characteristics of Ti-Based Biomedical Alloy by Electropolishing in Environmentally Friendly Deep Eutectic Solvent (Ethaline). Colloids Surf. A 2021, 613, 126125. [CrossRef]

34. Abbott, A.P.; Capper, G.; Swain, B.G.; Wheeler, D.A. Electropolishing of Stainless Steel in an Ionic Liquid. Trans. IMF 2005, 83, 51-53. [CrossRef]

35. Abbott, A.P.; Capper, G.; McKenzie, K.J.; Ryder, K.S. Voltammetric and Impedance Studies of the Electropolishing of Type 316 Stainless Steel in a Choline Chloride Based Ionic Liquid. Electrochim. Acta 2006, 51, 4420-4425. [CrossRef]

36. Abbott, A.P.; Capper, G.; McKenzie, K.J.; Glidle, A.; Ryder, K.S. Electropolishing of Stainless Steels in a Choline Chloride Based Ionic Liquid: An Electrochemical Study with Surface Characterisation Using SEM and Atomic Force Microscopy. Phys. Chem. Chem. Phys. 2006, 8, 4214-4221. [CrossRef]

37. Abdel-Fattah, T.M.; Loftis, J.D.; Mahapatro, A. Ionic Liquid Electropolishing of Metal Alloys for Biomedical Applications. ECS Trans. 2010, 25, 57-61. [CrossRef]

38. Lebedeva, O.; Jungurova, G.; Kultin, D.; Kustov, L.; Zakharov, A.; Kalmikov, K.; Chernikova, E.; Krasovskiy, V. Ionic Liquids Based on the Imidazolium Cation in Platinum and Titanium Electropolishing. Green Chem. 2011, 13, 1004. [CrossRef]

39. Liu, X.; Chu, P.; Ding, C. Surface Modification of Titanium, Titanium Alloys, and Related Materials for Biomedical Applications. Mater. Sci. Eng. R Rep. 2004, 47, 49-121. [CrossRef]

40. Uda, T.; Tsuchimoto, K.; Nakagawa, H.; Murase, K.; Nose, Y.; Awakura, Y. Electrochemical Polishing of Metallic Titanium in Ionic Liquid. Mater. Trans. 2011, 52, 2061-2066. [CrossRef]

41. Bayagoob, A.Y.O. Nano Electrochemical Polishing of Titanium Alloy Using Ionic Liquid. Bachelor's Thesis, Universiti Teknologi PETRONAS, Tronoh, Perak, 2015.

42. Karim, W.O.; Juma, J.A.; Omer, K.M.; Salih, Y.M.; Hama Aziz, K.H.; Aziz, S.B. Electropolishing and Mirror-like Preparation of Titanium in Choline Chloride-Ethylene Glycol Mixture Liquid. Electrochemistry 2020, 88, 447-450. [CrossRef]

43. Karim, W.O.; Juma, J.A.; Omer, K.M.; Ahmad, N.N.; Kader, D.A.; Tofiq, B.B.; Aziz, S.B. Novel Electropolishing of Pure Metallic Titanium in Choline Chloride-Based Various Organic Solvents. Electrochemistry 2021, 89, 67-70. [CrossRef]

44. Bahtiar, M.A. Nano Polishing of Titanium Alloy with Ionic Liquid. Bachelor's Thesis, Universiti Teknologi PETRONAS, Tronoh, Perak, 2016.

45. Karim, W.O.; Aziz, S.B.; Brza, M.A.; Abdullah, R.M.; Kadir, M.F.Z. The Anodic Behaviour of Bulk Copper in Ethaline and 1-Butyl-3-Methylimidazolium Chloride. Appl. Sci. 2019, 9, 4401. [CrossRef]

46. Abdel-Fattah, T.M.; Loftis, J.D. Comparison of the Electrochemical Polishing of Copper and Aluminum in Acid and Acid-Free Media. ECS Trans. 2009, 25, 327-332. [CrossRef]

47. Abdel-Fattah, T.M.; Loftis, D. Surface Characterization of High-Purity Copper Electropolishing and Electrodeposition Treatments in an Ionic Liquid. Meet. Abstr. 2020, MA2020-02, 2997. [CrossRef]

48. Hou, Y.; Li, R.; Liang, J. Simultaneous Electropolishing and Electrodeposition of Aluminum in Ionic Liquid under Ambient Conditions. Appl. Surf. Sci. 2018, 434, 918-921. [CrossRef]

49. Kityk, A.A.; Protsenko, V.S.; Danilov, F.I.; Kun, O.V.; Korniy, S.A. Electropolishing of Aluminium in a Deep Eutectic Solvent. Surf. Coat. Technol. 2019, 375, 143-149. [CrossRef]

50. Hou, Y.; Li, R.; Liang, J.; Su, P.; Ju, P. Electropolishing of $\mathrm{Al}$ and $\mathrm{Al}$ Alloys in $\mathrm{AlCl}_{3}$ / Trimethylamine Hydrochloride Ionic Liquid Surf. Coat. Technol. 2018, 335, 72-79. [CrossRef]

51. Abdel-Fattah, T.M.; Loftis, J.D. Comparison of Electropolishing of Aluminum in a Deep Eutectic Medium and Acidic Electrolyte. Molecules 2020, 25, 5712. [CrossRef]

52. Jiang, Y.; Fang, L.; Luo, L.; Wang, X. Fundamental Aspects of Uranium Electropolishing in $\mathrm{AlCl}_{3}$-1-ethyl-3-Methylimidazolium Chloride Ionic Liquid. J. Electrochem. Soc. 2018, 165, E70-E75. [CrossRef]

53. Yuza, N.; Serizawa, N.; Katayama, Y. Electropolishing of Tin in an Amide-Type Ionic Liquid. J. Electrochem. Soc. 2021, 168, 036509. [CrossRef]

54. Tachikawa, N.; Serizawa, N.; Katayama, Y.; Miura, T. Electrochemistry of Sn(II)/Sn in a Hydrophobic Room-Temperature Ionic Liquid. Electrochim. Acta 2008, 53, 6530-6534. [CrossRef]

55. Serizawa, N.; Tachikawa, N.; Katayama, Y.; Miura, T. EQCM Measurement of Sn(II)/Sn Reaction in 1-Butyl-1-Methylpyrrolidinium Bis(Trifluoromethylsulfonyl)Amide Room-Temperature Ionic Liquid. Electrochemistry 2009, 77, 630-632. [CrossRef]

56. Abdel-Fattah, T.M.; Loftis, J.D. Surface Characterization of High Purity Metals of Silver and Nickel Electropolished with an Ionic Liquid. ECS Trans. 2010, 25, 57-61. [CrossRef]

57. Karim, W.O.; Abbott, A.P.; Cihangir, S.; Ryder, K.S. Electropolishing of Nickel and Cobalt in Deep Eutectic Solvents. Trans. IMF 2018, 96, 200-205. [CrossRef]

58. Goddard, A.J.; Harris, R.C.; Saleem, S.; Azam, M.; Hood, C.; Clark, D.; Satchwell, J.; Ryder, K.S. Electropolishing and Electrolytic Etching of Ni-Based HIP Consolidated Aerospace Forms: A Comparison between Deep Eutectic Solvents and Aqueous Electrolytes. Trans. IMF 2017, 95, 137-146. [CrossRef]

59. Shabalovskaya, S.A. Surface, Corrosion and Biocompatibility Aspects of Nitinol as an Implant Material. BioMed. Mater. Eng. 2002, 12, 69-109.

60. Abbott, A.P.; Dsouza, N.; Withey, P.; Ryder, K.S. Electrolytic Processing of Superalloy Aerospace Castings Using Choline Chloride-Based Ionic Liquids. Trans. IMF 2012, 90, 9-14. [CrossRef] 
61. Mohammadian, N.; Turenne, S.; Brailovski, V. Electropolishing of Laser Powder Bed-Fused IN625 Components in an Ionic Electrolyte. J. Manuf. Mater. Process. 2019, 3, 86. [CrossRef]

62. Loftis, J.D.; Abdel-Fattah, T.M. Nanoscale Electropolishing of High-Purity Nickel with an Ionic Liquid. Int. J. Miner. Metall. Mater. 2019, 26, 649-656. [CrossRef]

63. Protsenko, V.S.; Butyrina, T.E.; Bobrova, L.S.; Korniy, S.A.; Danilov, F.I. Enhancing Corrosion Resistance of Nickel Surface by Electropolishing in a Deep Eutectic Solvent. Mater. Lett. 2020, 270, 127719. [CrossRef]

64. Loftis, J.D.; Abdel-Fattah, T.M. Nanoscale Electropolishing of High-Purity Silver with a Deep Eutectic Solvent. Colloids Surf. A 2016, 511, 113-119. [CrossRef]

65. Abdel-Fattah, T.M.; Crooks, R. Surface Characterization of High Purity Niobium Electropolished with an Ionic Liquid. ECS Trans. 2010, 33, 571-574. [CrossRef]

66. Wixtrom, A.I.; Buhler, J.E.; Reece, C.E.; Abdel-Fattah, T.M. Reclamation of Niobium Compounds from Ionic Liquid Electrochemical Polishing of Superconducting Radio Frequency Cavities. J. Environ. Chem. Eng. 2013, 1, 18-22. [CrossRef]

67. Wixtrom, A.I.; Buhler, J.E.; Reece, C.E.; Abdel-Fattah, T.M. Electrochemical Polishing Applications and EIS of a Novel Choline Chloride-Based Ionic Liquid. ECS Trans. 2013, 50, 199-202. [CrossRef]

68. Wixtrom, A.I.; Buhler, J.E.; Reece, C.E.; Abdel-Fattah, T.M. Electrochemical Polishing Applications and EIS of a Vitamin B ${ }_{4}$-Based Ionic Liquid. J. Electrochem. Soc. 2013, 160, E22-E26. [CrossRef]

69. Pastushenko, V.B.; Malkova, O.V.; Palmieri, V.; Rossi, A.A.; Stivanello, F.; Yu, G. Fluorine Free Ionic Liquid Electropolishing of Niobium Cavities. Proc. SRF 2013, TUIOC013, 410-413.

70. Chu, Q.; Wu, A.; Tan, T.; Guo, H.; Xiong, P.; Huang, S.; He, Y. Electropolishing Behavior of Niobium in Choline Chloride-Based Deep Eutectic Solvents. Appl. Surf. Sci. 2021, 550, 149322. [CrossRef]

71. Kityk, A.A.; Danilov, F.I.; Protsenko, V.S.; Pavlik, V.; Boča, M.; Halahovets, Y. Electropolishing of Two Kinds of Bronze in a Deep Eutectic Solvent (Ethaline). Surf. Coat. Technol. 2020, 397, 126060. [CrossRef]

72. Kalmykov, K.B.; Dmitrieva, N.E.; Lebedeva, O.K.; Root, N.V.; Kultin, D.Y.; Kustov, L.M. Formation of a Regular Cellular Structure on the Surface of Zr67Ni30Si3 Alloy at Electrochemical Polishing in Ionic Liquids. Russ. Chem. Bull. 2016, 65, 2801-2804. [CrossRef]

73. Brooman, E.W. Ionic Liquids for Surface Finishing Processes. Plat. Surf. Finish. 2007, 7, 54-57. 